\title{
Material Consumption and Carbon Emissions Associated with the Infrastructure Construction of 34 Cities in Northeast China
}

\author{
Heming Wang, ${ }^{1,2}$ Yao Wang $\mathbb{D}^{1},{ }^{1}$ Cong Fan, ${ }^{1}$ Xinzhe Wang, ${ }^{1}$ Yao Wei, ${ }^{1}$ Zhihe Zhang, \\ Jiashi Wang, ${ }^{1}$ Fengmei $\mathrm{Ma}^{2,3}$ and Qiang Yue ${ }^{1}$ \\ ${ }^{1}$ State Environmental Protection Key Laboratory of Eco-Industry, Northeastern University, Shenyang, China \\ ${ }^{2}$ Commonwealth Scientific and Industrial Research Organisation (CSIRO), Canberra, Australia \\ ${ }^{3}$ College of Economics and Management, Shenyang Agricultural University, Shenyang, China
}

Correspondence should be addressed to Yao Wang; wangyao_2018@hotmail.com

Received 18 June 2020; Revised 27 July 2020; Accepted 5 August 2020; Published 7 October 2020

Guest Editor: Jianhong (Cecilia) Xia

Copyright $(92020$ Heming Wang et al. This is an open access article distributed under the Creative Commons Attribution License, which permits unrestricted use, distribution, and reproduction in any medium, provided the original work is properly cited.

Over the past three decades, China has experienced rapid economic growth along with a rapid increase in urbanization and living standards, leading to a boom in infrastructure demand. A large part of China's newly constructed infrastructure is through urban construction; thus, cities have become a major source of material consumption and carbon emissions. Understanding the relationship between material consumption, carbon emissions, and the economic growth of cities is key to ensuring that the construction of infrastructure satisfies the needs for both economic development and dematerialization. In this study, we first accounted for material consumption and the carbon emissions of infrastructure construction of 34 cities in Northeast China and characterized spatial and temporal changes from 2010-2017. The material use and carbon emissions of infrastructure construction declined by $34.6 \%$ and $30.2 \%$ during this period. Specifically, material consumption decreased from 305.2 million tonnes to 199.6 million tonnes, and carbon emissions decreased from 77.7 million tonnes to 54.3 million tonnes. Furthermore, we used a decoupling indicator to evaluate the decoupling of material consumption or carbon emissions from GDP in these cities. We found that most cities have achieved the absolute decoupling of material consumption and carbon emissions from GDP over the study period. Finally, we proposed several policy recommendations for promoting the sustainable development of the infrastructure of cities. To ensure that cities realize low-carbon urbanization, policymakers need to promote modular buildings and low-emission construction materials. This paper also serves as a practical reference for the improvement of relevant materials and carbon emissions management strategies for other developing regions.

\section{Introduction}

Infrastructure has a transformative impact on social development and living standards and provides a variety of services, including construction, energy, water, and waste management [1]. At the same time, it also provides a means of storage for the extraction of natural resources from the environment. The scale of Chinese infrastructure construction has shown unprecedented growth to meet the growing demands of society and the economy and accommodate the continual improvement in living standards. However, the widespread use of construction materials has an important impact on resource consumption [2-4].
Furthermore, infrastructure development also results in substantial resource-related and environmental problems, such as increasing the scarcity of natural resources [5], land use [6], climate change [7], mercury emissions $[8,9], \mathrm{SO}_{2}$ emissions [10], and $\mathrm{CO}_{2}$ emissions [11-14]. Related impacts can also occur during the construction phase (materials production, manufacturing, and construction), in the use phase, and finally in the post-construction phase when infrastructure needs to be replaced $[15,16]$. These impacts are especially notable for China. Indeed, investment and construction of infrastructure have grown rapidly since the start of the gradualist economic reform in 1978, as the economy has developed rapidly and the average income of citizens has 
increased [17]. Construction in China accounts for nearly half of the world's new buildings on an annual basis [18, 19]. There is no doubt that these construction activities directly lead to increases in the overall level of $\mathrm{CO}_{2}$ emissions in China. However, the key to slowing global warming is to control and reduce $\mathrm{CO}_{2}$ emissions. China has pledged to reduce the $\mathrm{CO}_{2}$ per unit of GDP by $60-65 \%$ of the 2005 level by 2030 [20]. To achieve this goal, understanding the current status and characteristics of carbon emissions during infrastructure construction is imperative.

Cities have become the center of economic and social activities at the country and regional level after the Industrial Revolution, and the development of urban infrastructure provides the foundation for the operation and development of cities. Over the past 30 years, China's infrastructure development has rapidly developed, as the scale of investment, the scope of construction, and the construction level of infrastructure have continuously increased. A large part of China's newly constructed infrastructure consists of urban construction to accommodate urban economic activities and urban expansion [21, 22]. Construction materials, such as steel and cement, are the most utilized resources in urban areas after water by mass $[4,23]$. Therefore, a deeper understanding of the relationship between material consumption and $\mathrm{CO}_{2}$ emissions in the context of the economic development of China's urban infrastructure construction is crucial for low-carbon development and policymaking.

In recent years, a number of papers have investigated material flows and stocks at various scales, including global [24-26], national [27, 28], regional [29], and urban levels [30-32]. Material flow analysis is the most popular and standardized approach for analyzing inflow and outflow data, such as the import, export, and transfer of material in a system $[33,34]$. This method can be further divided into topdown and bottom-up approaches, which are used to study the relationship between material flow and $\mathrm{CO}_{2}$ emissions. Remote sensing (RS) and geographic information system (GIS) tools have also been used to address data shortages and to compile local infrastructure information to study material flow at different spatial scales.

In Table 1, we provide a summary of the material flows in infrastructure studies at different scales, temporal scopes, and sector coverage. Additionally, research on the material flow of infrastructure has also been focused on the $\mathrm{CO}_{2}$ emissions of construction. For example, Shi and Huang measured the $\mathrm{CO}_{2}$ emissions associated with the construction of China's buildings and road network using dynamic material flow analysis [38, 54]. Guo studied the stock changes and lifecycle greenhouse gas emissions (GHG) emissions of the urban road system, showing that the two major periods with GHG emissions are production and maintenance [55].

Although these studies provide a solid foundation of accounting methods and have enhanced our understanding of material flows and $\mathrm{CO}_{2}$ emissions associated with infrastructure, a few major gaps remain that require further research. First, these previous studies have mostly focused on the embodied $\mathrm{CO}_{2}$ emissions associated with a single type of infrastructure or material in a specific area rather than the infrastructure system as a whole at the city level. Second, the relationship between material consumption, the carbon emissions of infrastructure construction, and economic development has been seldom discussed. Third, few studies have examined cities in Northeast China. In China, a large number of people have moved from rural areas to cities. This, along with economic development, has led to the increased development of infrastructure and, in turn, the consumption of more materials and the emission of more $\mathrm{CO}_{2}$. Therefore, understanding the material consumption and carbon emissions associated with infrastructure construction is important for promoting the sustainable development of cities.

Here, we used a bottom-up accounting method to estimate the material consumption of seven major infrastructures and 10 types of materials, estimate the $\mathrm{CO}_{2}$ emissions of infrastructure construction, and analyze the relationship between material consumption, $\mathrm{CO}_{2}$ emissions, and GDP in 34 selected cities in Northeast China. Specifically, we aimed to thoroughly characterize material consumption and carbon emissions as well as identify potential ways for optimizing infrastructure resources and promoting sustainable urbanization.

\section{Methods and Data}

2.1. Study Area. The prefecture-level city is one of the major administrative divisions in China between the level of the province and county. Northeast China consists of three provinces-Liaoning, Jilin, and Heilongjiang-each of which includes 14, eight, and 12 prefecture-level cities, respectively. The study area in this paper includes all 34 prefecture-level cities in the three provinces of Northeast China (Figure 1). By 2017, these 34 cities in Northeast China had approximately $7.3 \%$ of the country's population and contributed to $6.3 \%$ of national GDP (http://www.stats.gov. $\mathrm{cn}$ ), demonstrating the important role that this region plays in the Chinese economy. The list of prefecture-level cities for each province is shown in Table 2.

2.2. Data Sources. This article divides the infrastructure of China into three main units based on their importance and availability of data: building, transportation, and public facility (Figure 2). The dataset included infrastructure-related data for 34 prefecture-level cities in the three northeastern provinces of China in 2010, 2012, 2015, and 2017. Statistical data regarding the size of their subtypes, including the floor areas of newly built residential and non-residential buildings, length of road systems, tap water pipelines, sewer pipelines, gas distribution pipelines, and street lamp data, were primarily collected from Statistical Yearbooks published by local statistical departments and institutes [56-59] and the "China Urban Construction Statistical Yearbook (2010-2018)." Population data for cities came from the annual average population estimates noted in the "China Statistical Yearbook (2010-2018)," which represented the population that was using urban infrastructure. The ten main types of construction materials were considered for 
TABLE 1: Studies on the material flow of infrastructure. Top-down = top-down account method. Bottom-up = bottom-up account method. $\mathrm{RS}=$ remote sensing. GIS = geographical information system.

\begin{tabular}{|c|c|c|c|c|c|c|}
\hline Scale & Method & Study area & Temporal scope & Material & Sector coverage & Reference \\
\hline \multirow[t]{2}{*}{ Global } & Top-down & Global & $1900-2010$ & $\begin{array}{l}\text { Construction } \\
\text { materials }\end{array}$ & $\begin{array}{l}\text { Buildings, infrastructure, and } \\
\text { machinery }\end{array}$ & {$[25]$} \\
\hline & RS & Global & 2012 & Steel & Buildings and infrastructure & [39] \\
\hline \multirow{8}{*}{ Country } & $\begin{array}{l}\text { GIS-based } \\
\text { bottom-up }\end{array}$ & Japan & $1945-2010$ & $\begin{array}{l}\text { Construction } \\
\text { materials }\end{array}$ & Buildings and infrastructure & {$[40]$} \\
\hline & Bottom-up & $\begin{array}{l}\text { The United States and } \\
\text { Japan }\end{array}$ & $1930-2005$ & $\begin{array}{l}\text { Construction } \\
\text { materials }\end{array}$ & Buildings & {$[41]$} \\
\hline & Bottom-up & China & $1950-2050$ & $\begin{array}{l}\text { Construction } \\
\text { materials }\end{array}$ & Buildings and transport network & {$[36]$} \\
\hline & $\begin{array}{l}\text { GIS-based } \\
\text { bottom-up }\end{array}$ & Japan & $1965-2010$ & $\begin{array}{c}\text { Construction } \\
\text { materials }\end{array}$ & Buildings and infrastructure & {$[42]$} \\
\hline & Bottom-up & China & $2000-2010$ & Steel & Buildings & {$[43]$} \\
\hline & Bottom-up & EU25 & 2004-2009 & $\begin{array}{l}\text { Construction } \\
\text { materials }\end{array}$ & $\begin{array}{l}\text { Residential buildings and } \\
\text { transportation networks }\end{array}$ & {$[44]$} \\
\hline & Bottom-up & China & $1900-2100$ & Steel & Buildings & [45] \\
\hline & Top-down & Japan & $1970-2000$ & $\begin{array}{c}\text { Construction } \\
\text { materials }\end{array}$ & Buildings & {$[46]$} \\
\hline \multirow{2}{*}{ Region } & Bottom-up & 31 provinces in China & $1978-2008$ & $\begin{array}{c}\text { Construction } \\
\text { materials }\end{array}$ & $\begin{array}{l}\text { Residential buildings and } \\
\text { infrastructure }\end{array}$ & {$[47]$} \\
\hline & RS & 30 provinces in China & 1992-2008 & $\begin{array}{c}\text { Construction } \\
\text { materials }\end{array}$ & Buildings and infrastructure & {$[48]$} \\
\hline \multirow{8}{*}{ City } & $\begin{array}{l}\text { GIS-based } \\
\text { bottom-up }\end{array}$ & Vienna (Austria) & $1918-2013$ & $\begin{array}{l}\text { Construction } \\
\text { materials }\end{array}$ & Buildings & {$[49]$} \\
\hline & Bottom-up & Rio de Janeiro (Brazil) & 2010 & $\begin{array}{l}\text { Construction } \\
\text { materials }\end{array}$ & Residential buildings & {$[50]$} \\
\hline & $\begin{array}{l}\text { GIS-based } \\
\text { bottom-up }\end{array}$ & Chiclayo (Peru) & 2007 & $\begin{array}{l}\text { Construction } \\
\text { materials }\end{array}$ & Buildings & {$[51]$} \\
\hline & $\begin{array}{l}\text { GIS-based } \\
\text { bottom-up }\end{array}$ & Wakayama (Japan) & $1855-2004$ & $\begin{array}{l}\text { Construction } \\
\text { materials }\end{array}$ & Buildings & {$[52]$} \\
\hline & Bottom-up & Beijing (China) & 1949-2008 & $\begin{array}{l}\text { Construction } \\
\text { materials }\end{array}$ & Residential buildings & {$[53]$} \\
\hline & Bottom-up & $\begin{array}{l}\text { Beijing, Shanghai, and } \\
\text { Tianjin (China) }\end{array}$ & $1978-2013$ & $\begin{array}{l}\text { Construction } \\
\text { materials }\end{array}$ & Buildings and infrastructure & {$[54]$} \\
\hline & $\begin{array}{l}\text { GIS-based } \\
\text { bottom-up }\end{array}$ & Philadelphia (US) & 2004-2012 & $\begin{array}{c}\text { Construction } \\
\text { materials }\end{array}$ & Buildings & {$[55]$} \\
\hline & RS & Canberra (Australia) & $1955,1981,2015$ & $\begin{array}{c}\text { Construction } \\
\text { materials }\end{array}$ & Buildings & {$[56]$} \\
\hline
\end{tabular}

accounting, as they reflect the specificity of the infrastructure. The material intensity of each type of infrastructure and material was compiled from published literature (Table S1). The carbon emission intensity of construction materials was estimated by calculating the carbon emission coefficient. The carbon emission intensity of construction materials was expressed as the $\mathrm{CO}_{2}$ emitted per unit of construction materials during production and processing from the life cycle assessment (LCA) database and published papers. Additional carbon emission intensity data are shown in Table S2.

2.3. Estimates of Material Consumption and Embodied Carbon Emissions. The material consumption of infrastructure construction was calculated using the bottom-up accounting method. The mathematical equations used to estimate
China's infrastructure construction material consumption and embodied carbon emissions were the following:

$$
S_{i, j}^{k}=A_{j}^{k} \times \mathrm{MI}_{i, j},
$$

where $S$ is the building material consumption, $A$ is the new floor space of buildings completed, and MI is the material intensity. The indices $k, i$, and $j$ are the year, building functional type, and construction material type, respectively.

$$
R_{a, j}^{k}=P_{a, j}^{k} \times \mathrm{MI}_{a, j}+N_{a, j}^{k} \times \mathrm{MI}_{a, j},
$$

where $R$ is the material consumption for roads, $P$ is the length of newly constructed road, and $N$ is the road maintenance length. The indices $k$ and $a$ are the year and type of road, respectively.

$$
G_{c, j}^{k}=Q_{c, j}^{k} \times \mathrm{MI}_{c, j}
$$




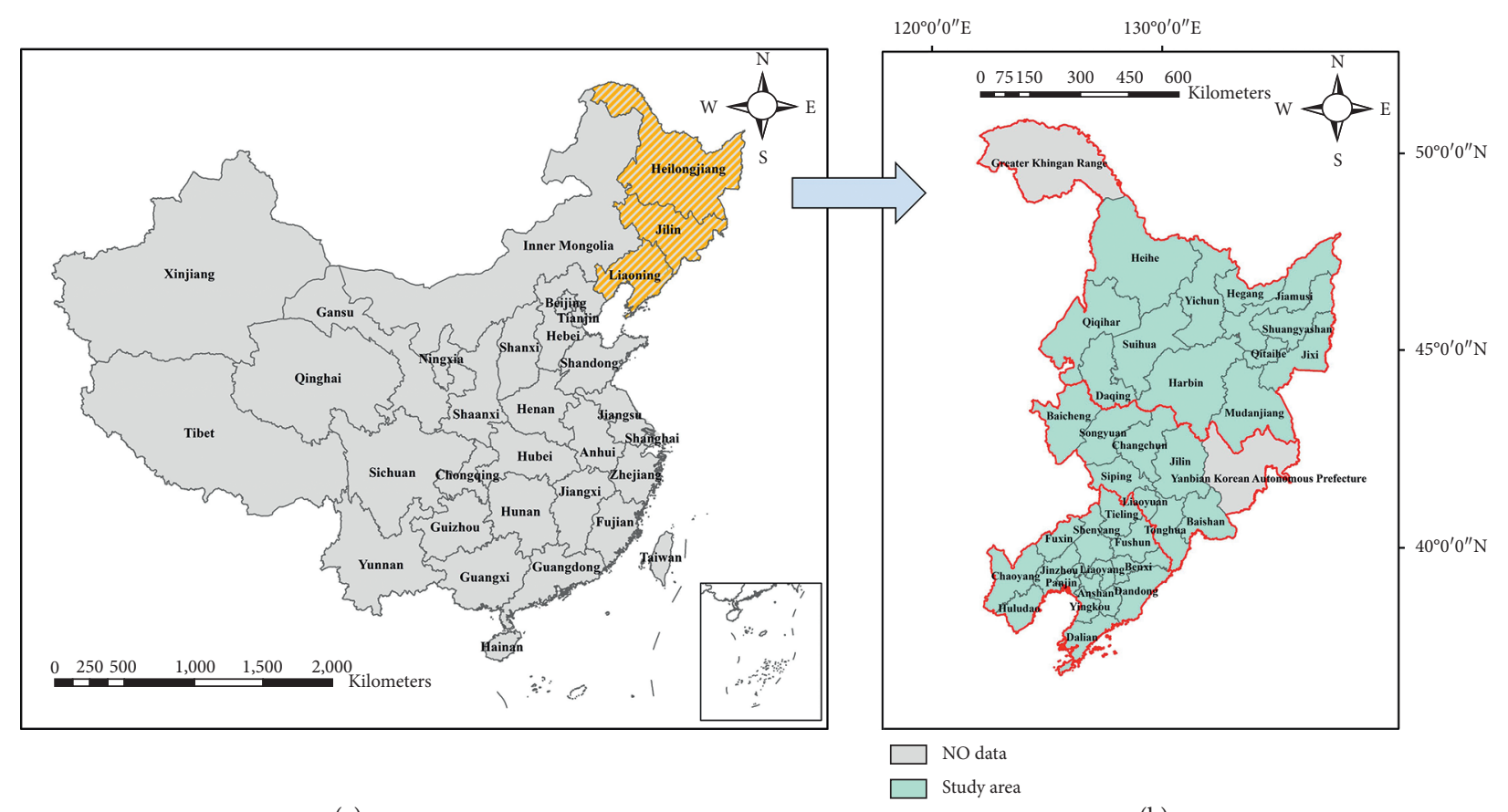

(a)

(b)

Figure 1: Map of the study area.

TABLE 2: Cities within each of the three provinces of Northeast China examined in this study.

\begin{tabular}{lc}
\hline Provinces & Prefecture-level cities covered \\
\hline Liaoning & Shenyang, Dalian, Anshan, Fushun, Benxi, Dandong, Jinzhou, Yingkou, Fuxin, Liaoyang, Panjin, Tieling, Chaoyang, \\
Jilin & Huludao \\
Heilongjiang & Changchun, Jilin, Siping, Liaoyuan, Tonghua, Baishan, Songyuan, Baicheng \\
\hline
\end{tabular}

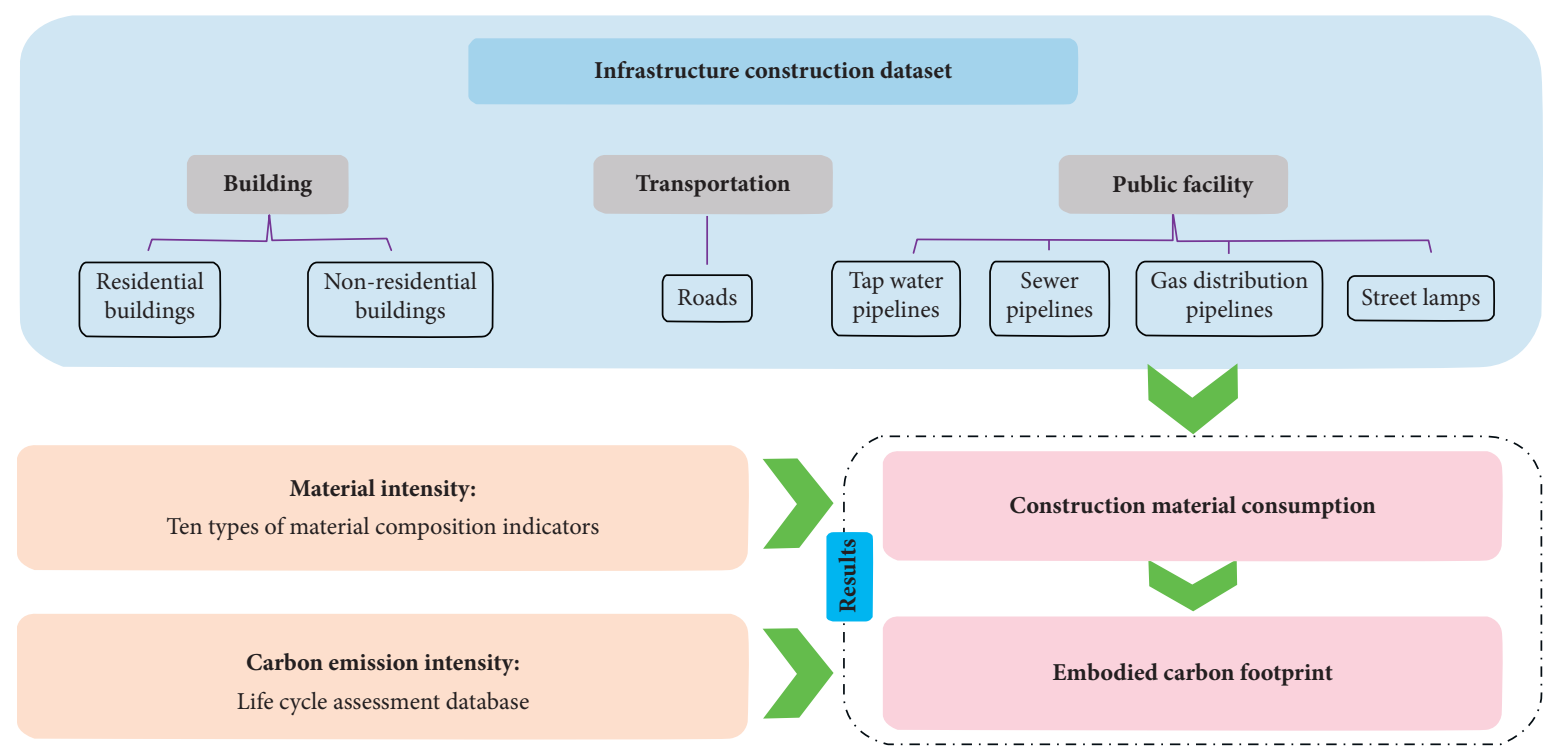

FIGURE 2: The framework underlying the material consumption and carbon emissions of infrastructure construction. 
where $G$ is the material consumption of public facilities and $Q$ is the newly added length or unit of public facilities. The index $c$ corresponds to the type of public facility.

$$
E^{k}=\sum_{j} S_{i, j}^{k} \times e_{j}+\sum_{j} R_{a, j}^{k} \times e_{j}+\sum_{j} G_{c, j}^{k} \times e_{j},
$$

where $E$ is the embodied carbon of infrastructure construction and $e$ is the embodied carbon emissions intensity of the material.

2.4. Decoupling Indicator. The decoupling analysis method was used to provide an indicator for analyzing the degree to which environmental load and economic growth were decoupled. In recent years, growing concerns relating to resource use and climate change have prompted organizations to use decoupling analysis for research and development [60]. "Decoupling" involves breaking the link between environmental hazards and economic development. Generally, there are two modes of decoupling: resource decoupling (or dematerialization) and decreasing negative environmental impacts, such as $\mathrm{CO}_{2}$ emissions. Lu et al. derived a pair of decoupling indicators for resource use and $\mathrm{CO}_{2}$ emissions from the IPAT equation [61-63]. The decoupling indicator is given by the following formula:

$$
D=\frac{t}{g} \times(1+g)
$$

where $D$ is decoupling indicator $\left(D_{\mathrm{m}}\right.$ represents the decoupling of the materials consumption of infrastructure construction and GDP, and $D_{\mathrm{e}}$ represents the decoupling of $\mathrm{CO}_{2}$ emissions of infrastructure construction and GDP), $g$ is the geometric average growth rate of GDP, and $t$ is the geometric average rate of decline in the material consumption or $\mathrm{CO}_{2}$ emissions per unit GDP. According to the values of $D\left(D_{\mathrm{m}}\right.$ or $\left.D_{\mathrm{e}}\right)$, the degree to which material consumption is decoupled from $\mathrm{CO}_{2}$ emissions and GDP can be divided into three states: absolute decoupling, relative decoupling, and non-decoupling (Table 3) [64].

\section{Results and Discussion}

3.1. Overview of Material Consumption. The ten categories of construction materials of the seven subtypes within the three types of infrastructure for 34 cities and trends of material consumption from 2010-2017 are shown in Figures 3 and 4. Over the past seven years, the total material consumption of infrastructure construction in 34 cities has decreased by $34.6 \%$ from 305.2 million tonnes in 2010 to 199.6 million tonnes in 2017. The overall trends can be divided into three stages. The growth rate of GDP $(33.8 \%)$ was faster than that of the consumption of construction materials (11.4\%) from 2010-2012 (Figure S1), indicating that the economic development caused by infrastructure construction has increased. From 2012-2015, GDP growth slowed sharply to $6.3 \%$. At the same time, the material consumption of infrastructure also showed negative growth, with the rate of decline reaching 10.3\%. However, from 2015-2017, the overall infrastructure material consumption and
TABLE 3: Division of the degree of decoupling based on the values of the decoupling indicator of material consumption or $\mathrm{CO}_{2}$ emissions $\left(D_{\mathrm{m}}\right.$ or $\left.D_{\mathrm{e}}\right)$.

\begin{tabular}{lcc}
\hline Degree of decoupling & Economic growth & Economic decline \\
\hline Absolute decoupling & $D \geq 1$ & $D \leq 0$ \\
Relative decoupling & $0<D<1$ & $0<D<1$ \\
Non-decoupling & $D \leq 0$ & $D \geq 1$ \\
\hline
\end{tabular}

construction scale of 34 cities, along with GDP, declined by $7.8 \%$ and $34.6 \%$, respectively. This decline primarily stems from the fact that the amount of infrastructure investment and the scale of construction in Northeast China are largely dependent on the development of local economies [65].

Buildings are the unit with the greatest amount of materials (Figure 3). At the same time, the improvement in living standards has promoted an increase in the construction of non-residential buildings; indeed, the annual material accumulation of non-residential buildings exceeds that of residential buildings every year. The second largest use comes from transportation, in which the share of total material consumption has increased slightly from $9.8 \%$ in 2010 to $16.2 \%$ in 2017. Transportation was followed by public facilities, including tap water pipelines, sewer pipelines, gas distribution pipes, and street lamps, which accounted for $5.1 \%$ of total material consumption in 2010 and $11.9 \%$ in 2017 . This increase may be related to the fact that the proportion of natural gas in China's primary energy consumption has increased to $10 \%$ by 2020 [66]. Construction of the China-Russia East Natural Gas Line began in 2015, and this project has undoubtedly led to the construction of public facilities [67].

Sand and gravel, cement, brick, and steel are the top four materials that have been accumulated for use in infrastructure, accounting for $96-98 \%$ of all materials used (Figure 4). Because of changes in the size of buildings constructed, the amount of cement used decreased from $16.9 \%$ in 2010 to $14.8 \%$ in 2017 . The proportion of steel consumption increased from $3.7 \%$ in 2010 to $5.8 \%$ in 2017 , reflecting the wide application of steel in infrastructure. The impact of infrastructure development on the environment is substantial, and these materials, including cement and steel, consume several different resources, such as fossil fuels and water, during the production process. Therefore, extending the lifespan of infrastructure with proper maintenance is necessary.

3.2. Spatiotemporal Variation in Material Use. The development of 34 cities in Northeast China has been uneven. Thus, analyzing the consumption of construction materials in different cities separately is necessary for characterizing the material management problems faced during the development of different cities.

The total consumption of infrastructure construction materials of cities in Northeast China is shown in Figure 5. Shenyang, Changchun, and Harbin were the largest consumers of construction materials, with total consumption more than 20 million tonnes within these cities in 2010 . 


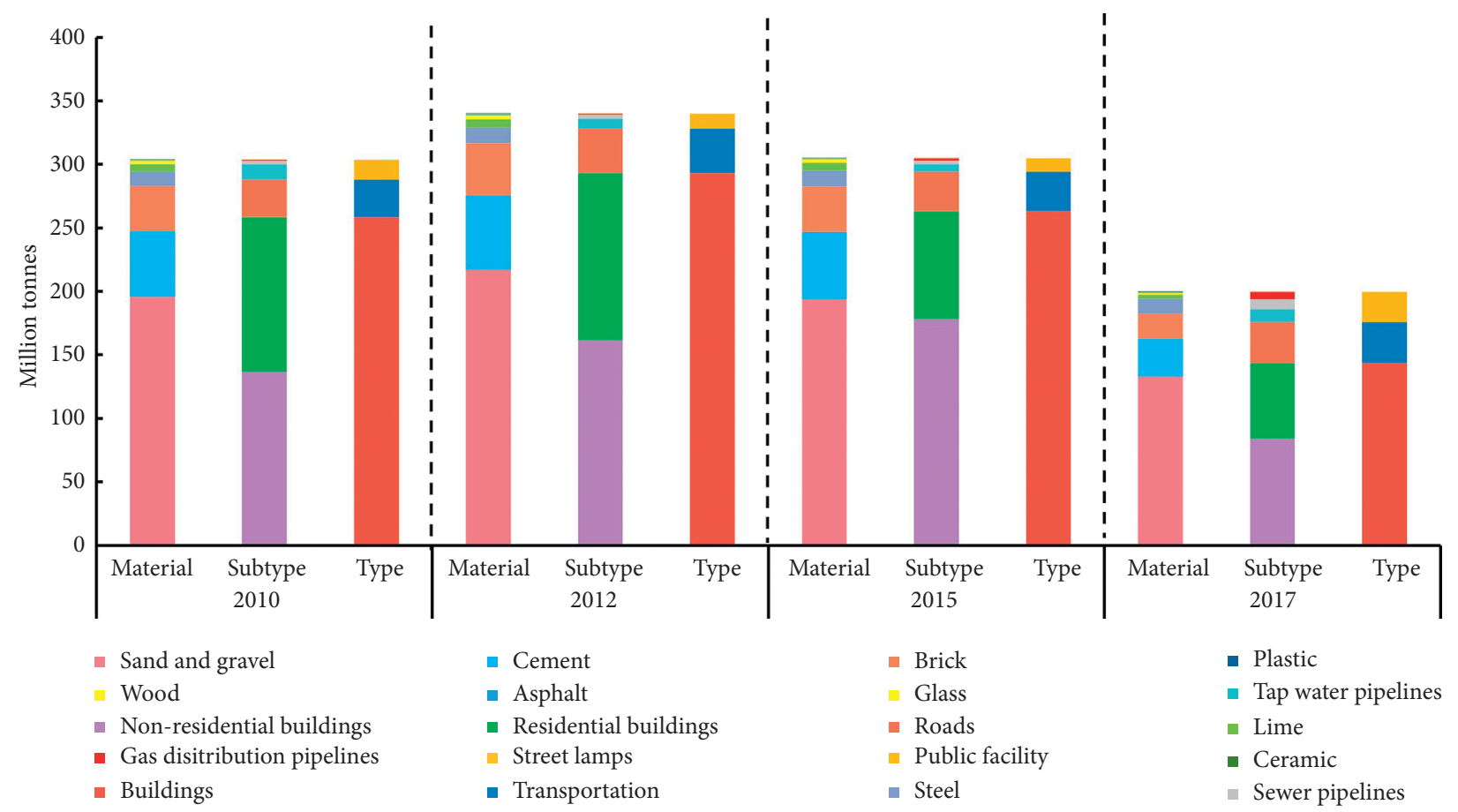

FIGURE 3: The distribution of material consumption structure across infrastructure types in 34 cities in Northeast China in 2010, 2012, 2015, and 2017.

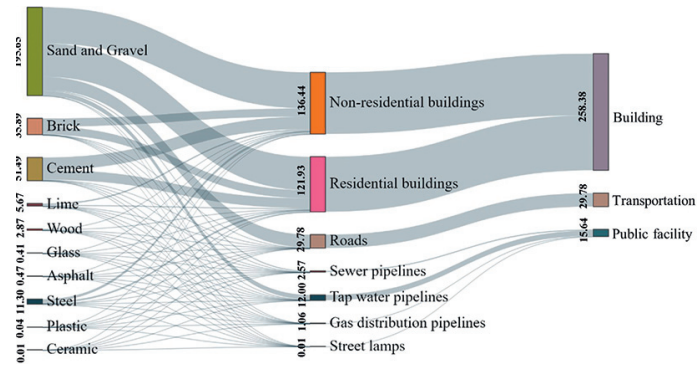

(a)

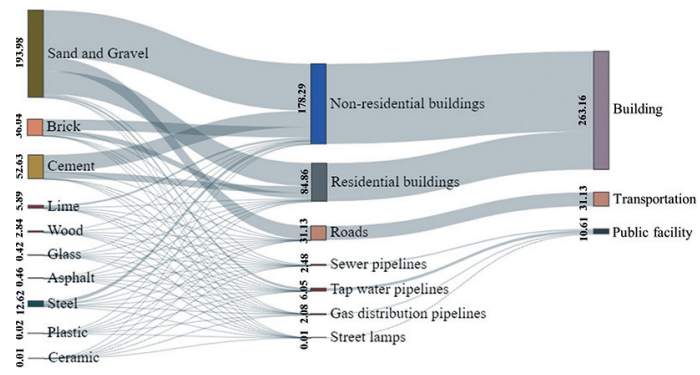

(c)

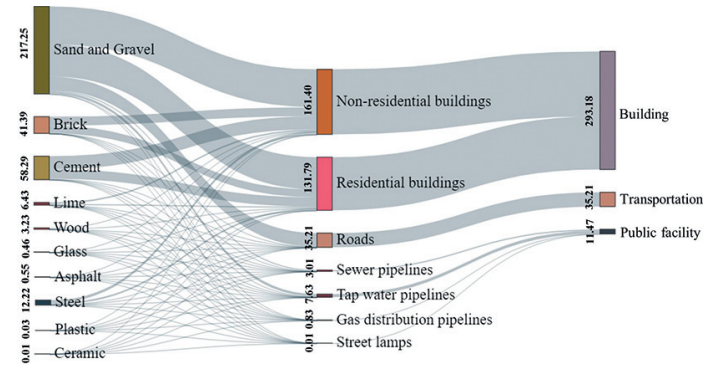

(b)

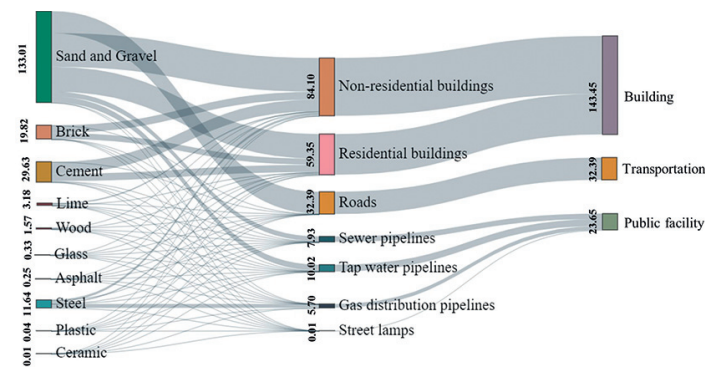

(d)

Figure 4: Distribution of construction material consumption across infrastructure types in 34 cities in Northeast China in 2010, 2012, 2015, and 2017. Note: the width of the streamline represents the amount of material consumption. (a) Year of 2010. (b) Year of 2012. (c) Year of 2015. (d) Year of 2017. The units in the figure are million tonnes.

Compared with 2010, most cities have reduced the consumption of infrastructure construction materials in 2017. However, cities with large total material consumption have still been concentrated in cities with greater degrees of economic development in the region, such as Changchun,
Shenyang, and Harbin, indicating that infrastructure construction is one of the factors driving economic development. Figure 6 shows the per capita consumption of urban infrastructure construction materials. The per capita material consumption in cities, such as Yingkou, 


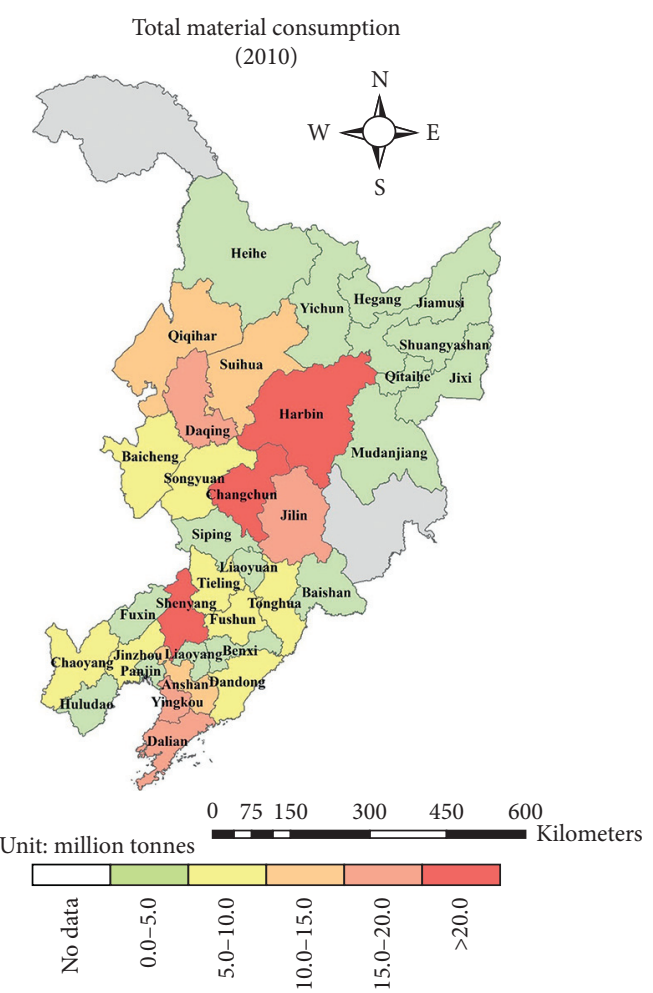

(a)

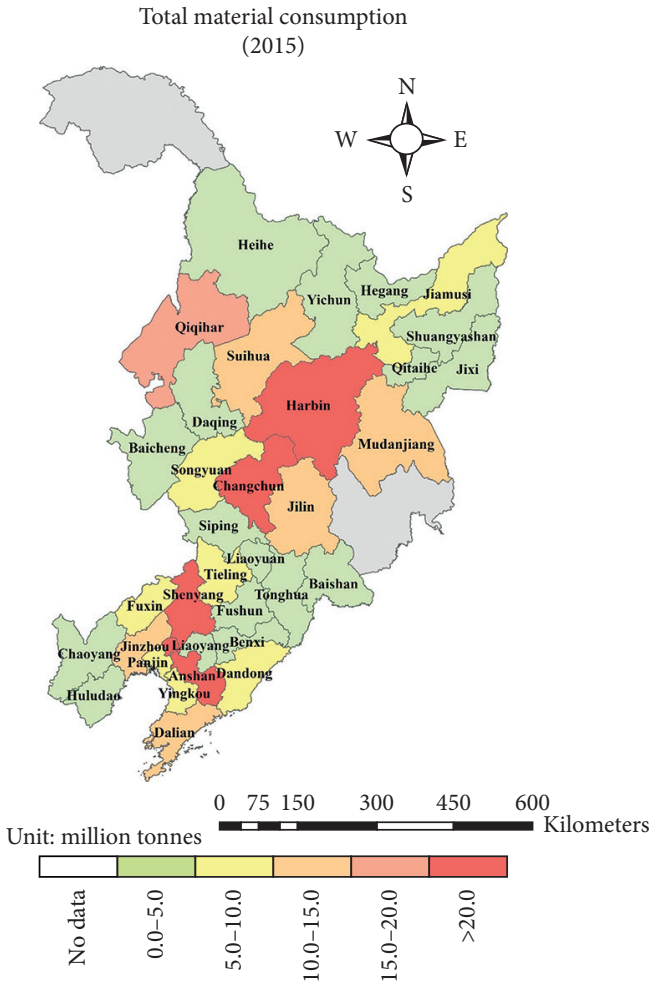

(c)

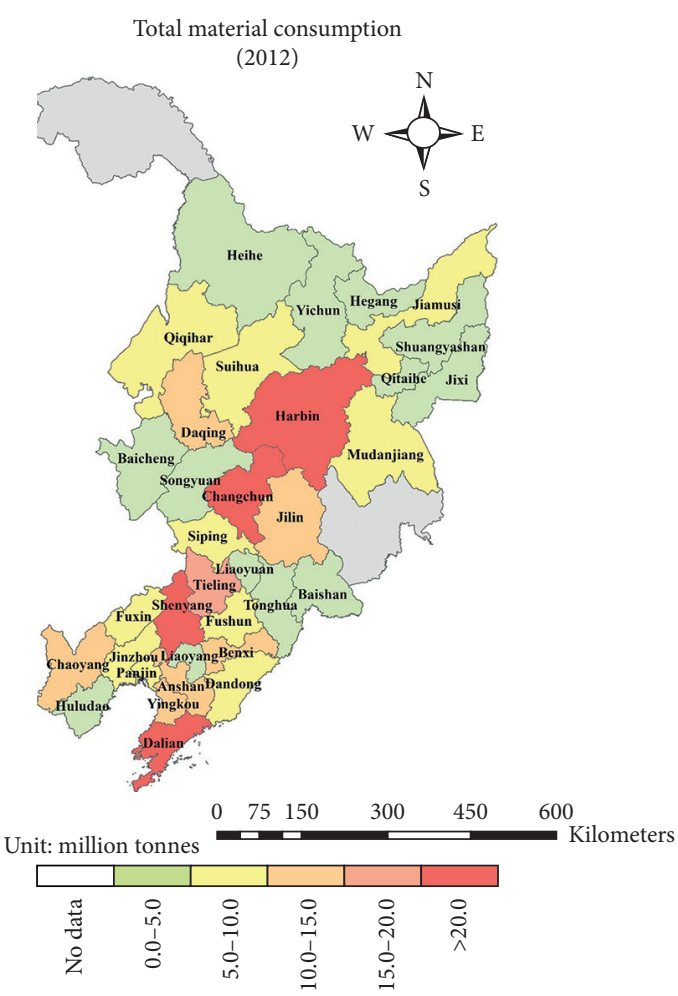

(b)

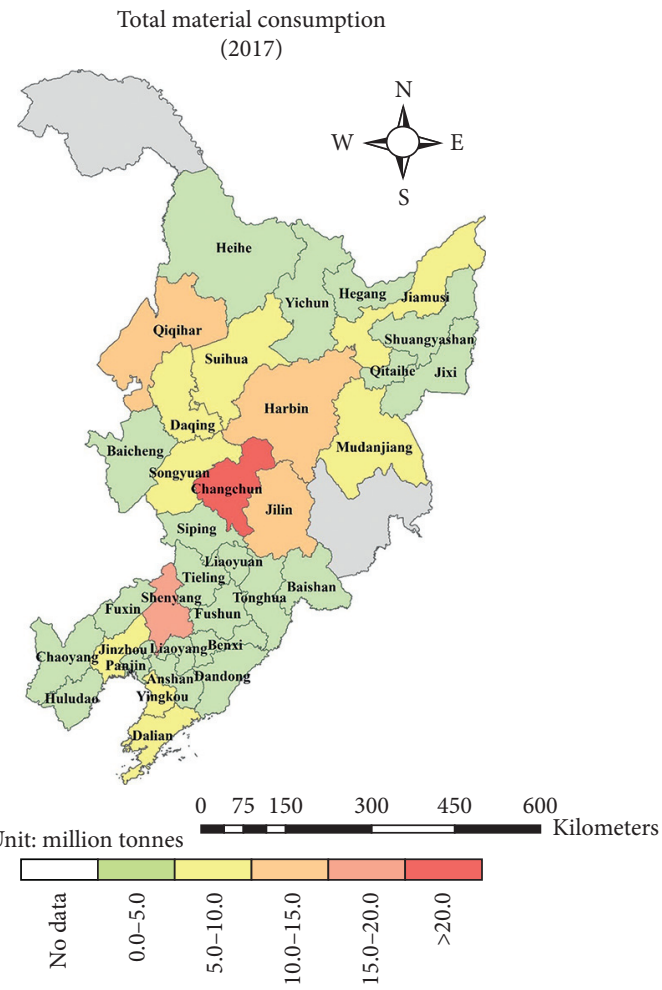

(d)

Figure 5: Spatial patterns of the total material consumption of infrastructure construction of 34 cities in Northeast China in 2010, 2012, 2015, and 2017. 


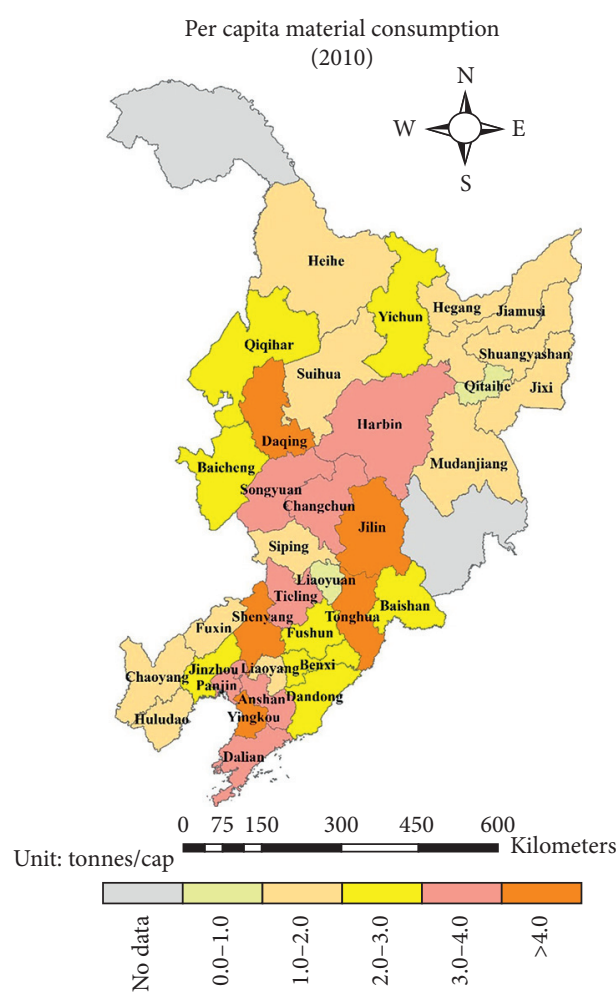

(a)

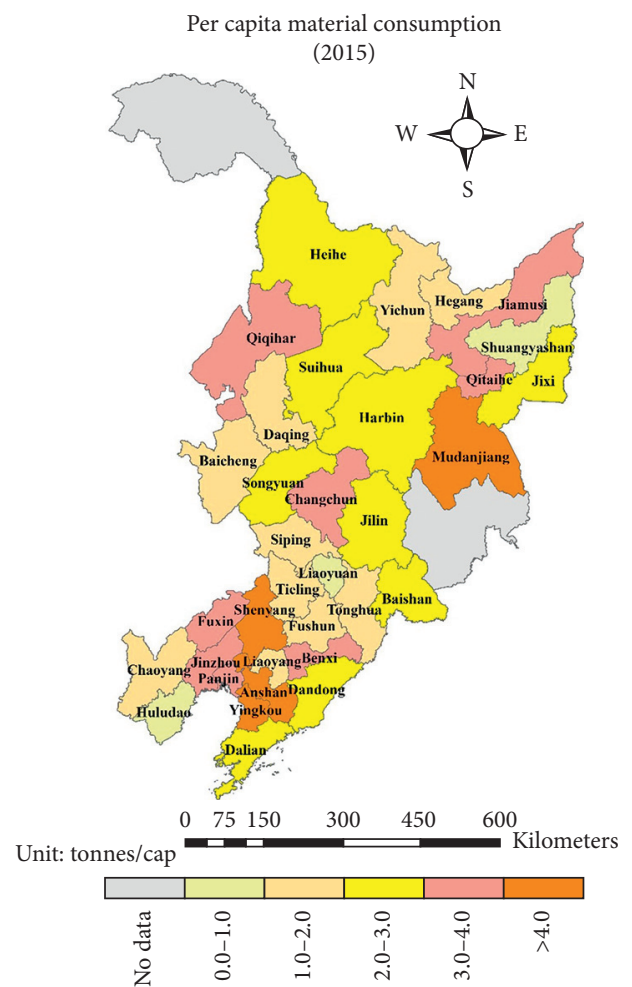

(c)

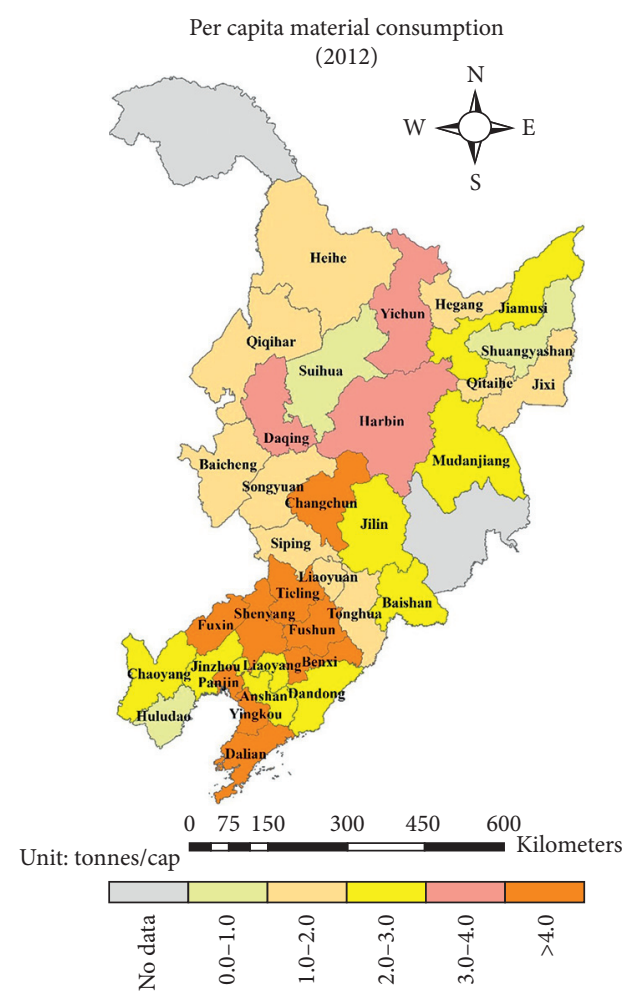

(b)

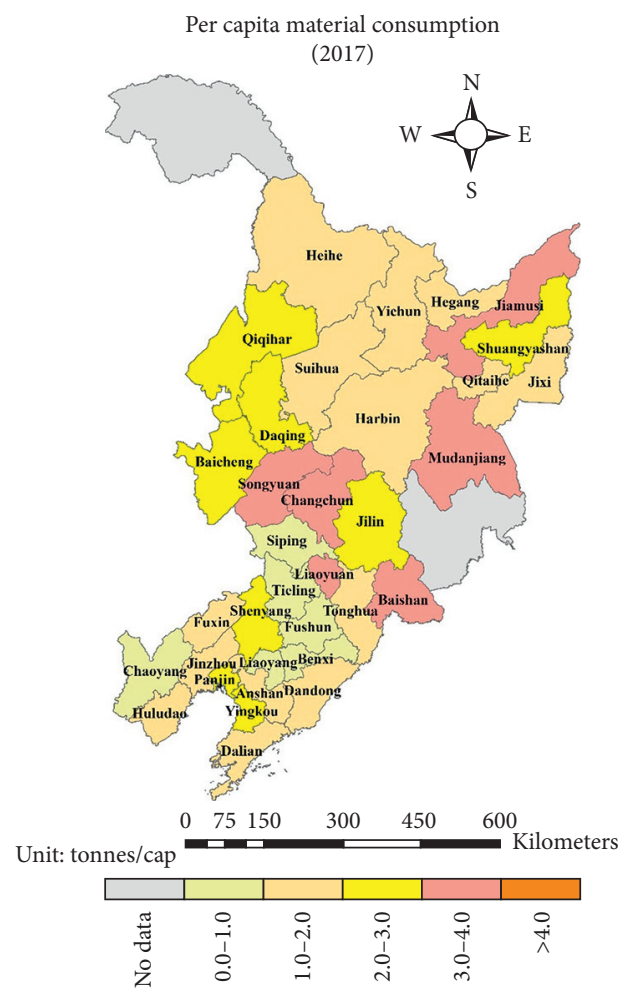

(d)

FiguRE 6: Spatial patterns of per capita material consumption of the infrastructure construction of 34 cities in Northeast China in 2010, 2012, 2015, and 2017. 
Daqing, and Shenyang, was much higher than the average use, which made these cities the largest per capita consumers of materials in 2010. In 2017, in contrast to the pattern for total material consumption, the top three largest per capita consumers of materials were Baishan, Changchun, and Mudanjiang. Per capita material consumption relative to the degree of infrastructure development reflected an uneven distribution of the scale of infrastructure construction across 34 cities in Northeast China. The distribution of total material consumption and per capita material consumption of infrastructure was consistent with the disparity in economic development across cities. In general, cities with a high degree of economic development, such as Shenyang, Changchun, and Harbin, can take full advantage of radiation effects to coordinate regional development.

For the 14 cities in Liaoning province, trends in the total material consumption and per capita material consumption of infrastructure construction can be divided into two stages. From 2010 to 2012, the 14 cities experienced rapid growth in the material use of infrastructure. The average rate of increase for this two-year period was $18.6 \%$. The average annual growth rates of infrastructure material consumption per capita and GDP were $18.9 \%$ and $15.3 \%$, respectively. During this period, the large-scale construction of infrastructure has promoted the development of the local economy and urbanization. In the second period from 2012-2017, total material consumption and per capita consumption declined at an average annual rate of $19.6 \%$ and $19.3 \%$, respectively. For the eight cities in Jilin province, total material consumption decreased between 2010 and 2015, while material consumption increased between 2015 and 2017. In contrast, total consumption and per capita consumption of infrastructure construction materials in Heilongjiang's 12 cities decreased from 2010-2017. The total material consumption decreased from 91 million tonnes in 2010 to 68 million tonnes in 2017. This decrease may stem from the fact that the average annual population decreased on an annual basis, and the decrease in the size of the city has been more pronounced.

Material intensity of use is an indicator of material efficiency that is most often expressed as the amount of material consumption per unit of economic output [68]. Greater material intensity of use corresponds to less efficiency in the degree to which material use contributes to GDP growth. Figure 7 shows the material intensity of use of urban infrastructure construction materials. From 2010 to 2017, cities with the highest GDP among the 34 cities, such as Dalian, Changchun, and Shenyang, had lower material intensity of use values, which usually corresponded to lower material intensities. Cities with a greater degree of economic development thus enjoy lower material consumption intensity, while several cities with higher total material consumption had higher material consumption intensity. Developing cities can improve resource efficiency by controlling the extensive sprawl of urban land, improving the compactness of cities, and reducing their dependence on materials [69].
3.3. Embodied Carbon Footprint. Based on the above analysis, steel, brick, and cement account for a large proportion of infrastructure materials, which are the primary causes of $\mathrm{CO}_{2}$ emissions and other toxic pollutants in the mining and manufacturing processes [70-72]. This paper further estimates the amount of $\mathrm{CO}_{2}$ emissions by the infrastructure construction activities of 34 cities. Figures 8 and 9 map the amount of total $\mathrm{CO}_{2}$ emissions and per capita $\mathrm{CO}_{2}$ emissions of 34 cities in Northeast China across several sample years. In 2010, Shenyang, Harbin, and Changchun had the highest levels of $\mathrm{CO}_{2}$ emissions, while Qitaihe, Liaoyuan, and Heihe had the lowest levels of $\mathrm{CO}_{2}$ emissions. Cities with the highest $\mathrm{CO}_{2}$ emissions generated from infrastructure construction were Shenyang, Changchun, and Harbin, which was consistent with the pattern observed in total material consumption across cities from 2010 to 2015. Similarly, during this period, most cities showed high levels of $\mathrm{CO}_{2}$ emissions stemming from the construction of infrastructure. The emissions per capita varied among cities because of differences in city size and material consumption. Shenyang showed the greatest change in per capita emissions among cities, which largely stemmed from its higher urbanization rate. However, changes in total $\mathrm{CO}_{2}$ emissions and per capita emissions were notable between 2015 and 2017 with most cities showing reduced $\mathrm{CO}_{2}$ emissions associated with reductions in infrastructure construction. A few exceptions, such as Changchun, still maintained a high level of $\mathrm{CO}_{2}$ emissions. During this period, the growth rate of GDP in most cities declined and even showed negative growth, leading to decreased investment in infrastructure construction. The reduction in infrastructure investment directly led to a decline in the scale of infrastructure construction. As a result, both total emissions and per capita emissions decreased. In addition, the reduction in material consumption intensity in each city improved material efficiency and played an important role in reducing the carbon footprint [25].

The carbon emissions intensity (CEI), defined as $\mathrm{CO}_{2}$ per unit of GDP, is an important indicator for capturing the relationship between carbon emissions and the economy [73]. For example, Shenyang is one of the highest emitters of $\mathrm{CO}_{2}$. In 2017, Shenyang's emission level was 1.3 times higher than that of Huludao's emission level. However, Huludao's CEI was 6.1 times higher than that of Shenyang's CEI. China's 13th Five-Year Plan (2016-2020) introduced a new national carbon intensity indicator assessment system and proposed energy reduction targets based on carbon intensity. Hence, focusing on CEI facilitates the consideration of $\mathrm{CO}_{2}$ mitigation strategies independent of their economic impact. Figure 10 shows the CEI distribution of 34 cities in Northeast China from 2010 to 2017. Overall, CEI decreased from 2010 to 2017. The three cities with the highest CEI values were Yingkou, Tonghua, and Suihua, which all exhibited CEI values greater than 0.3 tonnes $/ 10^{4} \mathrm{CNY}$ in 2010. By 2017, the CEI of most cities had declined to less than 0.2 tonnes $/ 10^{4} \mathrm{CNY}$. Notably, only Huludao continued to show a CEI above 0.4 tonnes $/ 10^{4} \mathrm{CNY}$, and this stability was driven in part by the lower degree of economic development in this city within Liaoning province. 
Material consumption intensity

(2010)

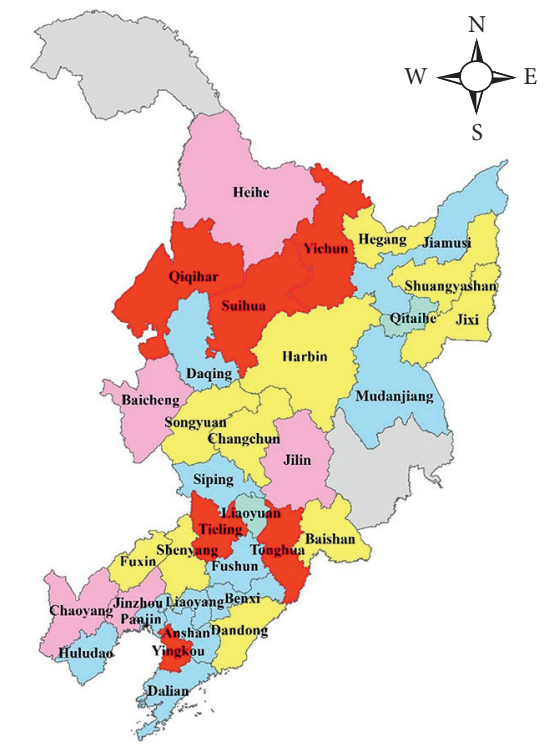

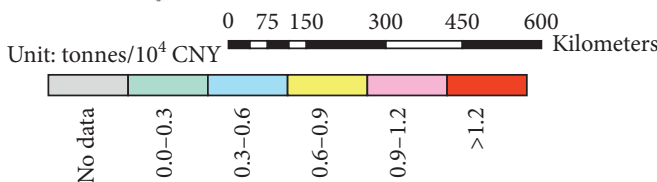

(a)

Material consumption intensity

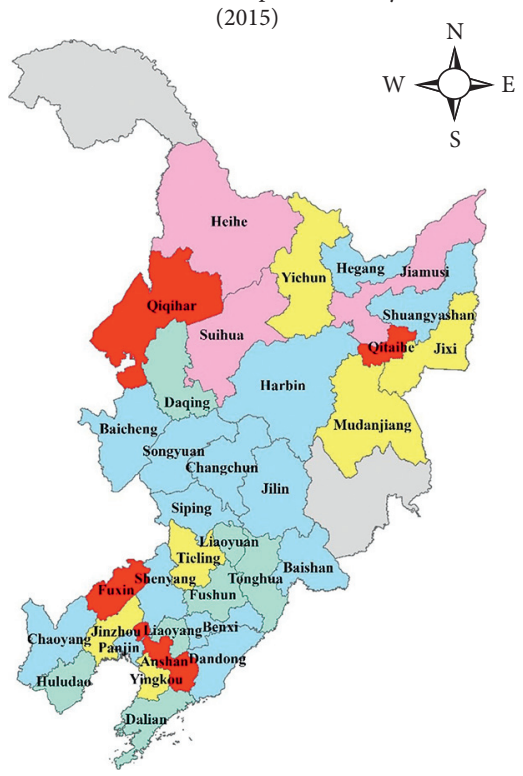

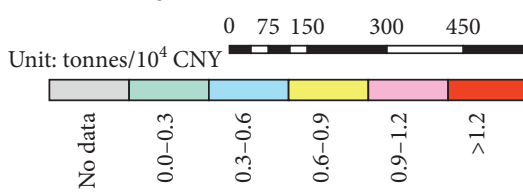

(c)
Material consumption intensity

(2012)

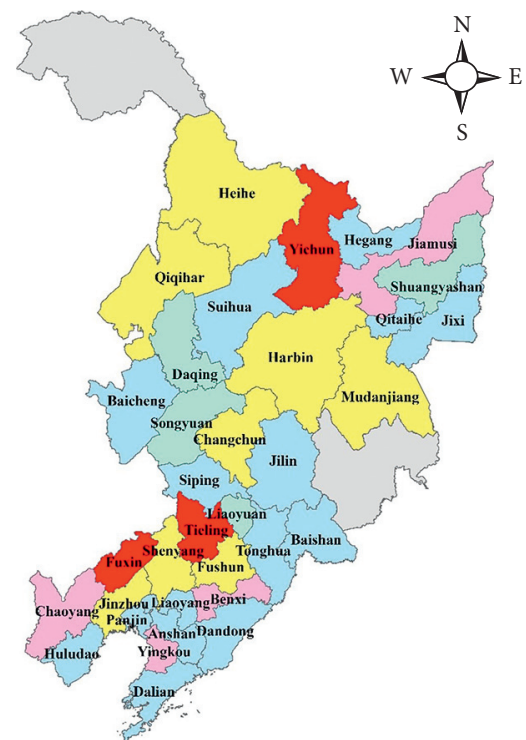

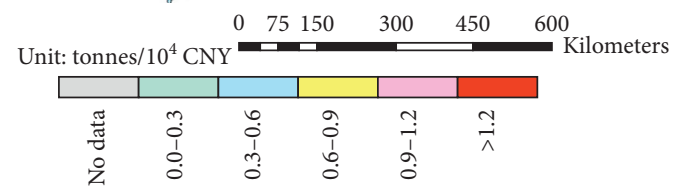

(b)

Material consumption intensity

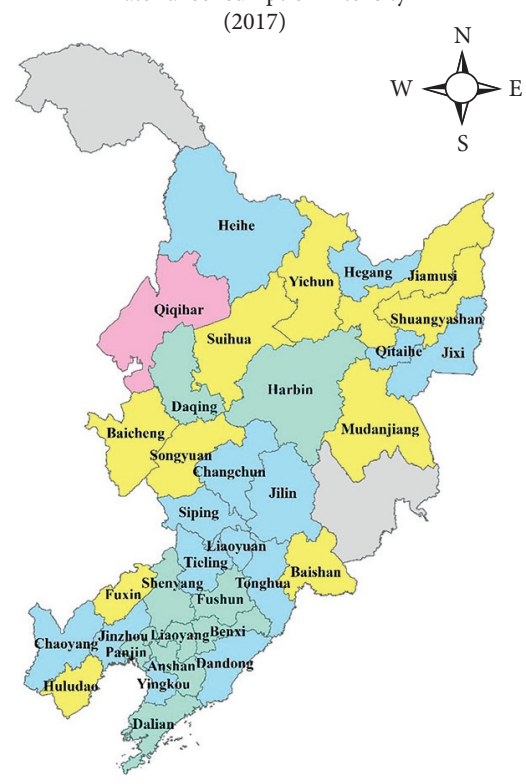

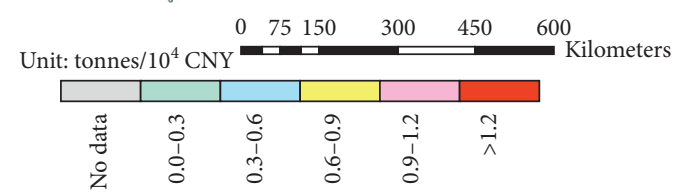

(d)

Figure 7: Spatial patterns of the material consumption intensity of infrastructure construction of 34 cities in Northeast China in 2010, 2012, 2015, and 2017. 


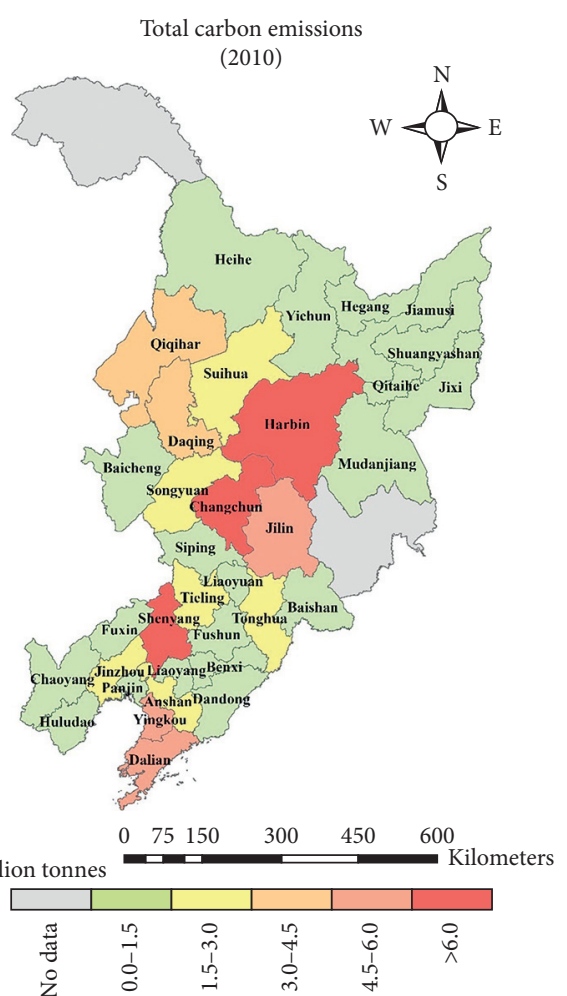

(a)

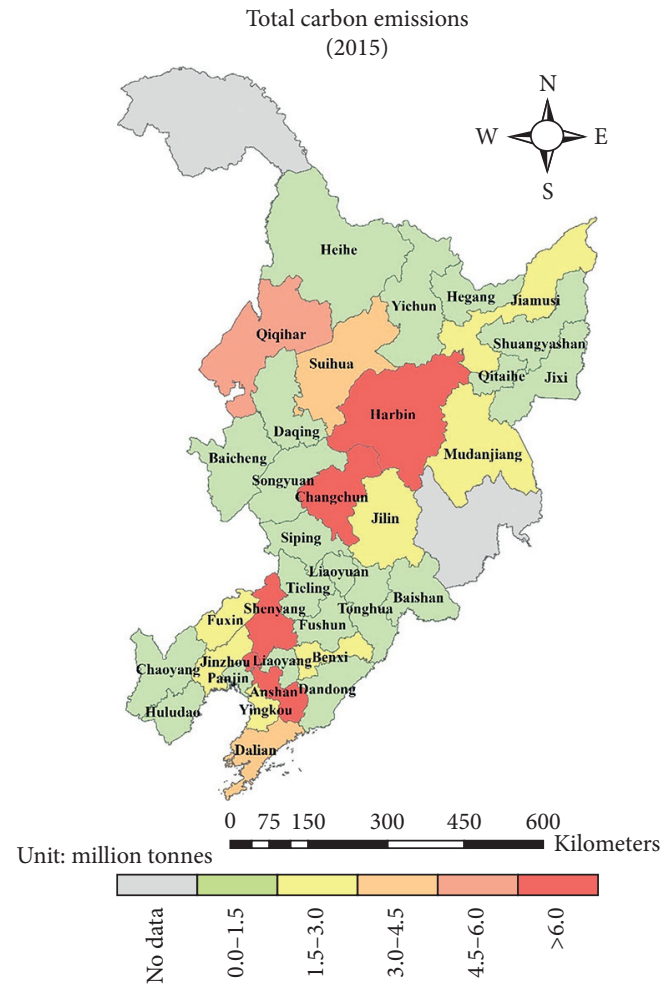

(c)

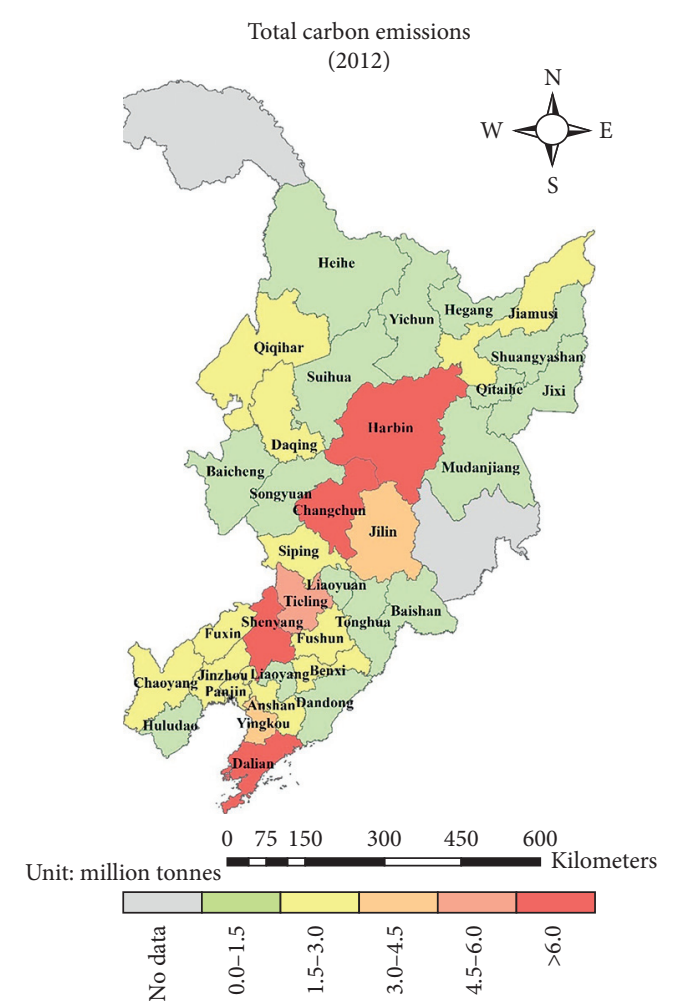

(b)

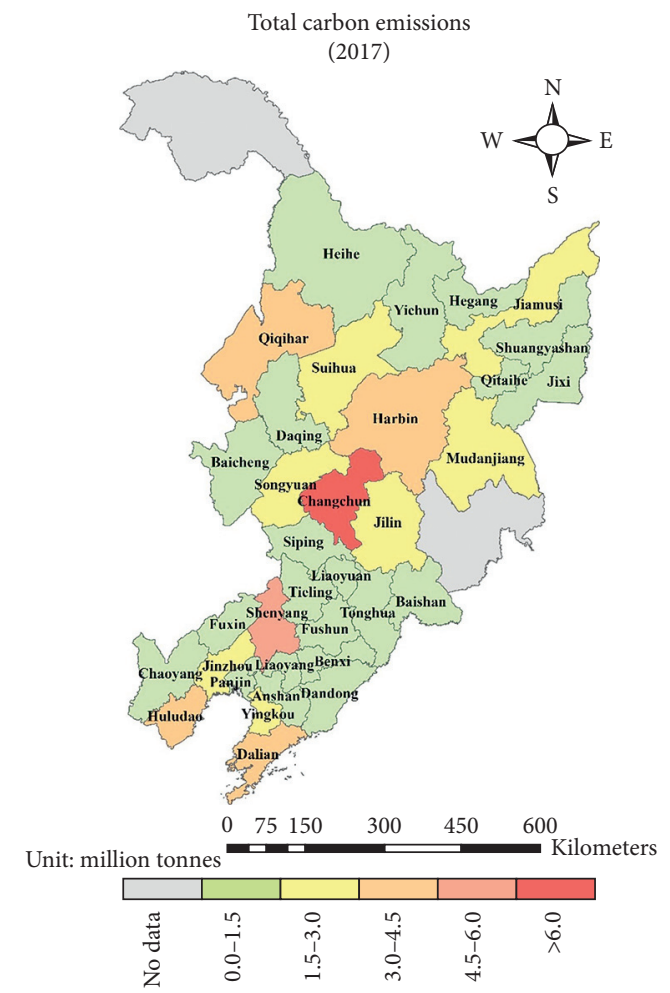

(d)

FIGURE 8: Spatial patterns of the total $\mathrm{CO}_{2}$ emissions associated with infrastructure construction of 34 cities in Northeast China in 2010, 2012, 2015, and 2017. 


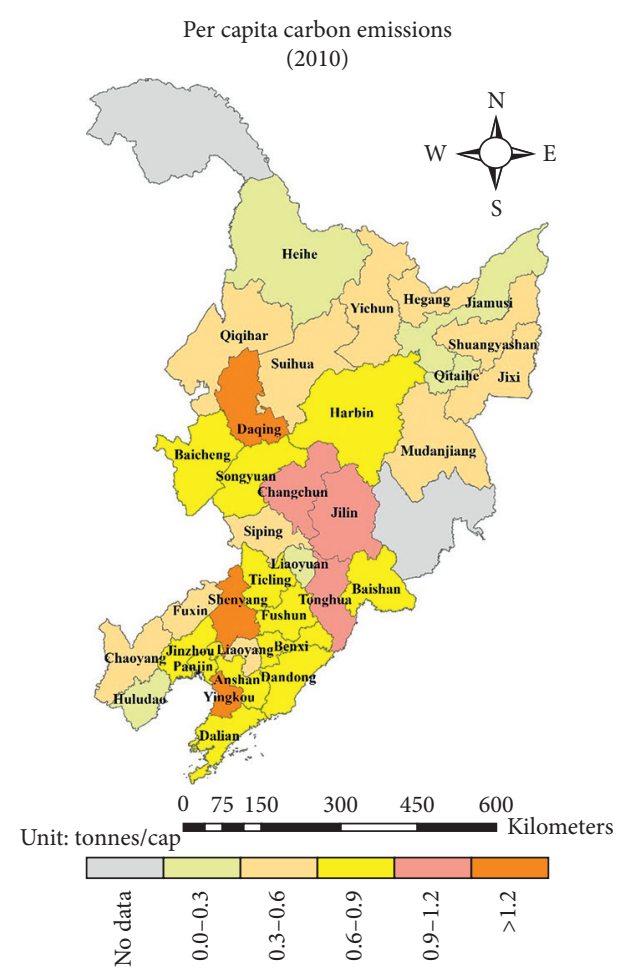

(a)

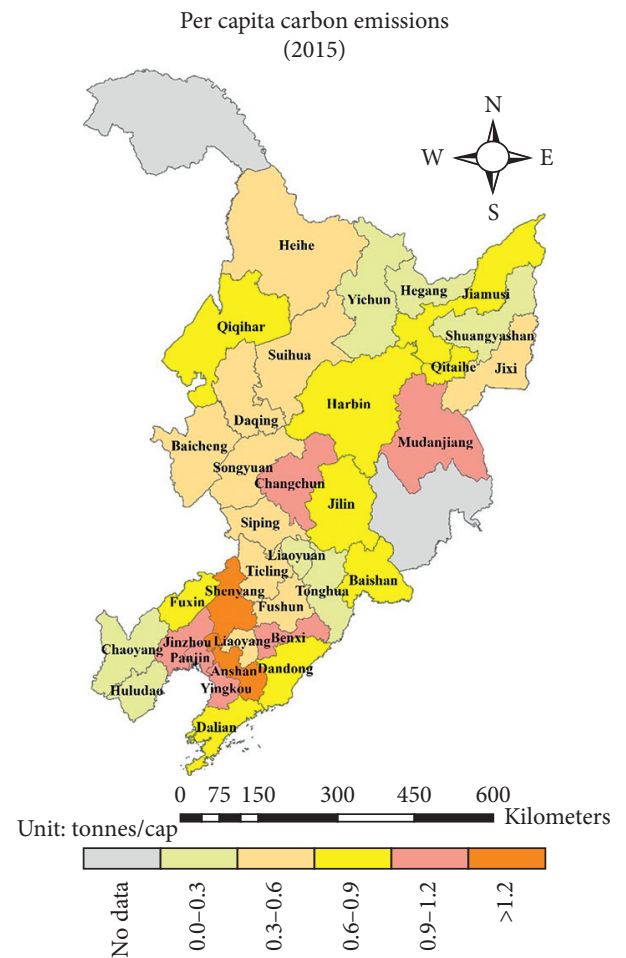

(c)

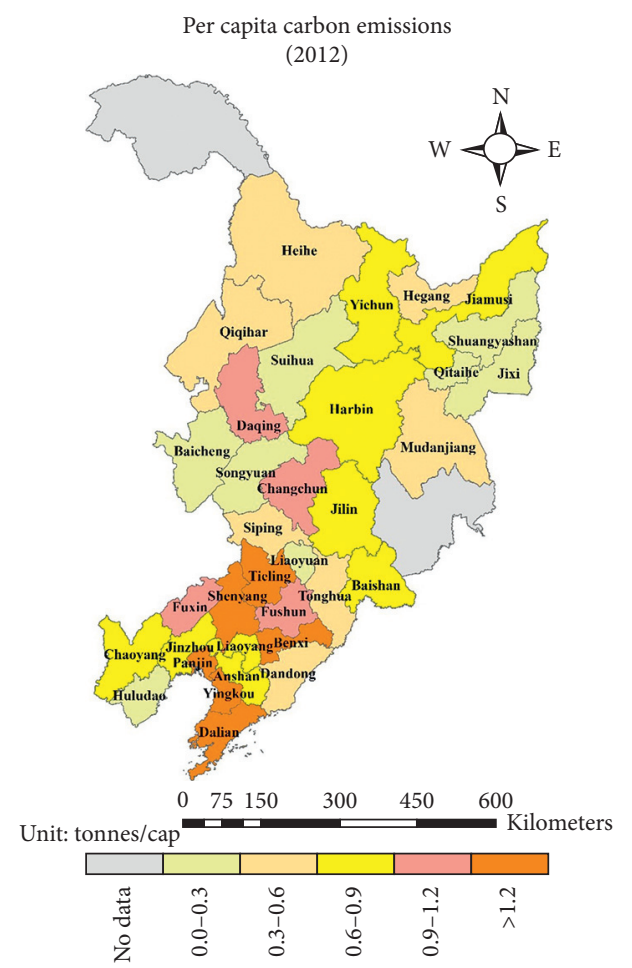

(b)

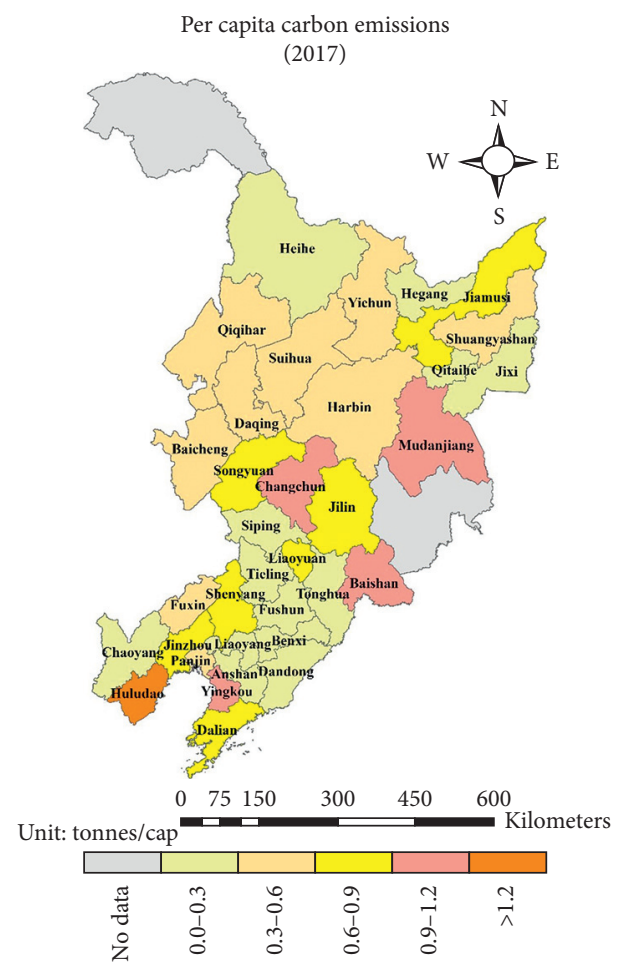

(d)

FIGURE 9: Spatial patterns of total per capita $\mathrm{CO}_{2}$ emissions of infrastructure construction of 34 cities in Northeast China in 2010, 2012, 2015, and 2017.

Among the 34 cities in Northeast China with greater degrees of economic development, Shenyang, Dalian, Changchun, and Harbin showed high levels of total emissions and per capita emissions from infrastructure construction, but CEI values were lower than the provincial average. This finding indicates that infrastructure tends to be 


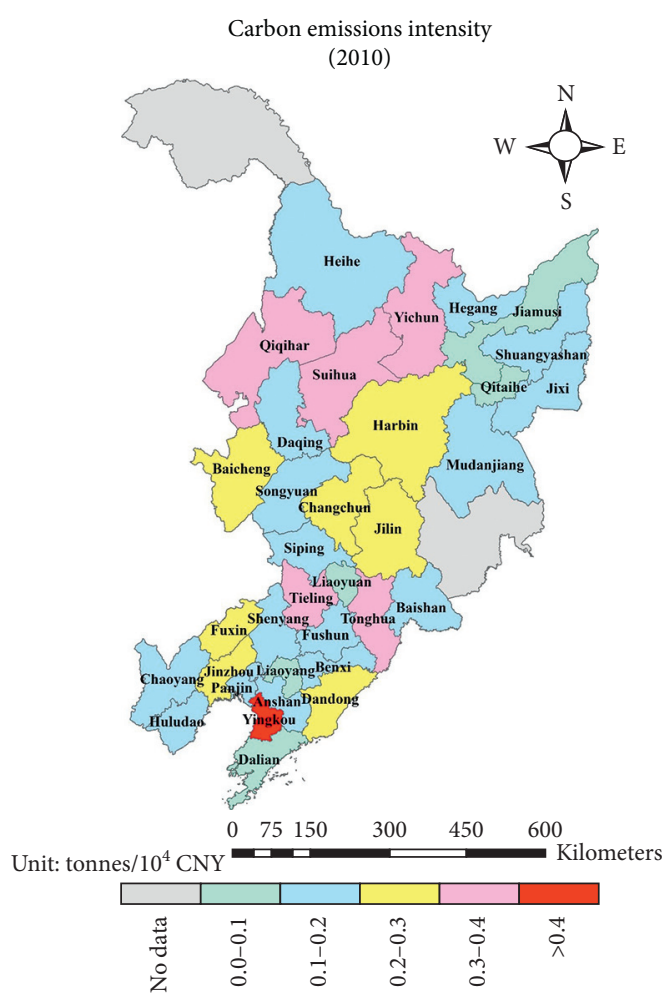

(a)

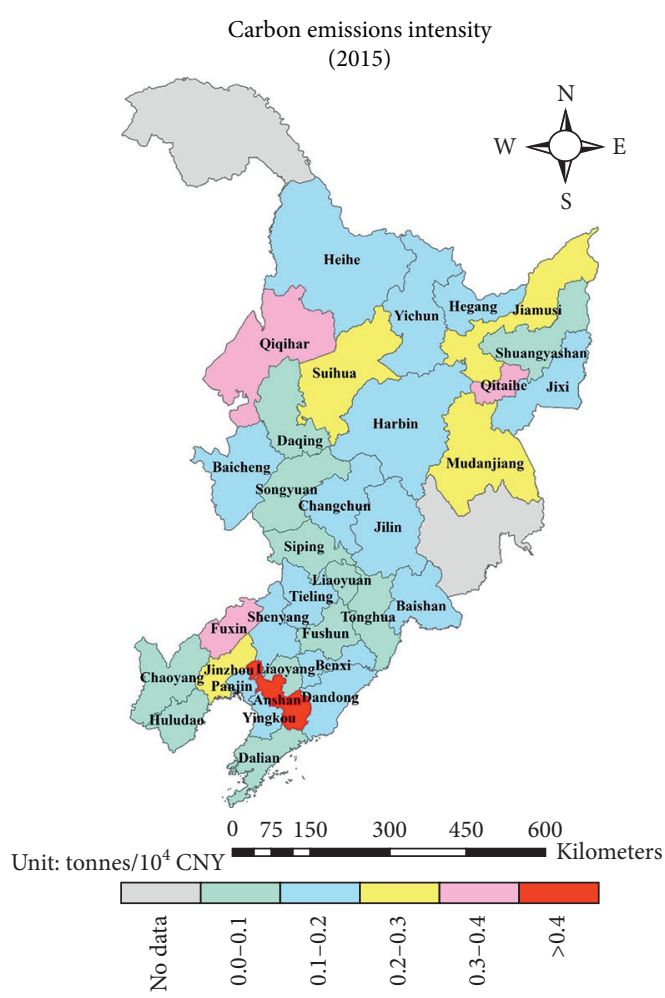

(c)

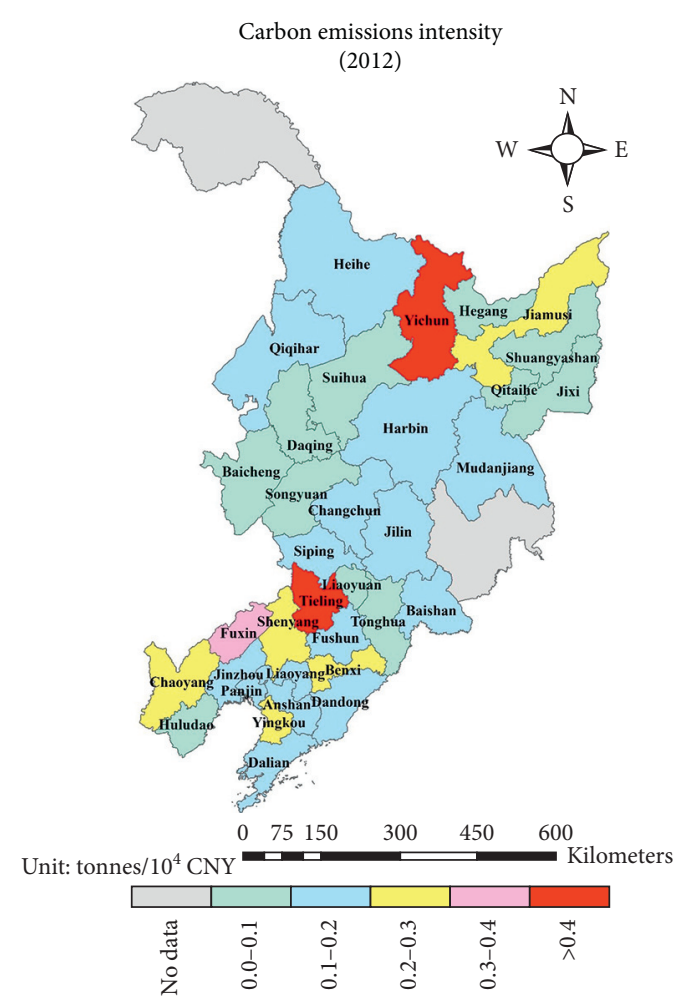

(b)

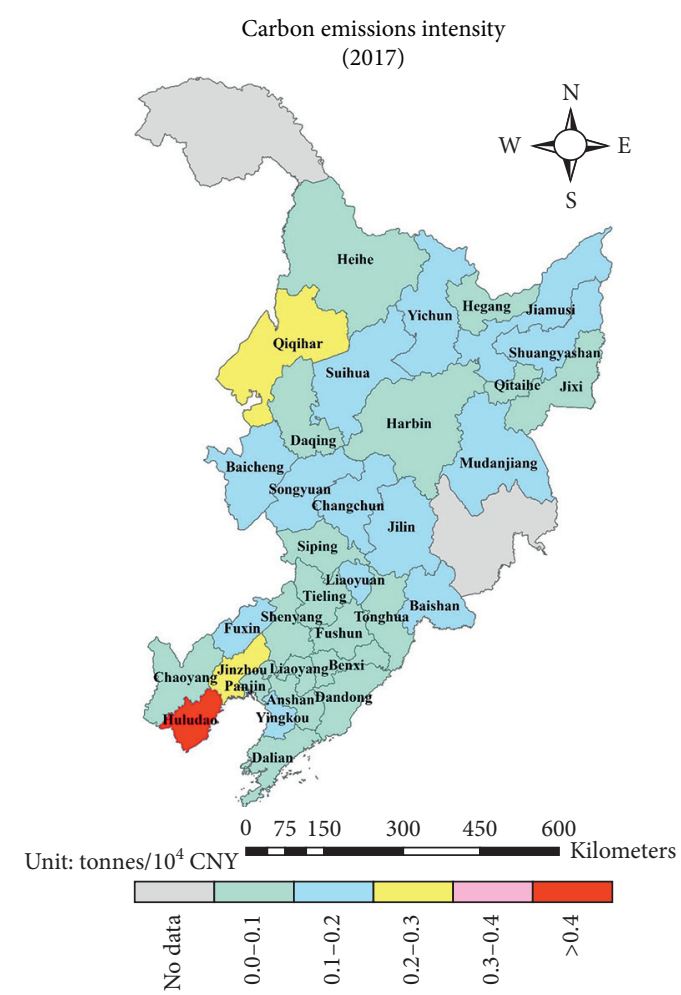

(d)

Figure 10: Spatial patterns of carbon emissions intensity (CEI) of infrastructure construction of 34 cities in Northeast China in 2010, 2012, 2015 , and 2017. 
built in cities showing robust economic performance that would thus profit more from urban economic services and technical development. In contrast, cities with higher CEI values showed much lower levels of infrastructure construction with lower levels of urbanization from 2010-2017.

3.4. Decoupling Analysis. Here, the results of the decoupling analysis of material consumption and the $\mathrm{CO}_{2}$ emissions of infrastructure construction from GDP in 34 cities of three provinces in Northeast China from 2010-2017 are presented. Based on GDP, material consumption, and carbon emissions data for 34 cities, we calculated the values of $g$ and $t$ for each city. The decoupling indicators $\left(D_{\mathrm{m}}\right.$ and $\left.D_{\mathrm{e}}\right)$ were calculated by equation (5). In this study, there is a strong correlation between material consumption and carbon emissions in infrastructure construction. The two decoupling states of each city will appear similar to some extent.

Figure 11 shows the decoupling of the material consumption of infrastructure construction from economic growth in 34 cities of Northeast China from 2010-2017. Among cities that showed economic growth during the study period, a total of 21 cities achieved the absolute decoupling of the material consumption of infrastructure construction from GDP growth. Among cities showing absolute decoupling, the decoupling level of Liaoyang was the highest $\left(D_{\mathrm{m}}\right.$ of 22.5). Meanwhile, cities that managed to decouple carbon emissions and GDP growth were also the same as those that had managed to decouple the material consumption of infrastructure built and GDP growth (Figure 12). During this period, the decoupling of these 10 cities indicates that there was an improvement in the sustainable infrastructure construction of economic development. Because of the slow economic growth (only 1-10\%), the government has focused on ensuring that the development of the economy is in harmony with the material consumption of infrastructure built and the environment, which has facilitated the growth of the economy to some extent but has reduced the pressure on the environment. Therefore, growth in material consumption and carbon emissions reduced, and the sustainability of development improved.

Songyuan, Baishan, and Qiqihar achieved the relative decoupling of the material consumption of infrastructure and carbon emissions of infrastructure construction and positive economic growth. The environmental impact also increased along with GDP, but the growth rate was lower than that of GDP. In this period, Huludao, Liaoyuan, Shuangyashan, Mudanjiang, and Jiamusi did not achieve the decoupling of the material consumption or carbon emissions from GDP, indicating that the growth rate of the environmental impact as a consequence of GDP growth has exceeded the growth rate in GDP. The eight cities in the relatively decoupling and non-decoupling areas were more dependent on infrastructure construction for economic development, but the problem was that the structure of economic development was relatively simple. Furthermore, economic growth was accompanied by an acceleration of environmental disruption.
Four cities had achieved the absolute decoupling of material consumption or carbon emissions of infrastructure construction and economy among cities with negative economic growth, which reduced the pressure on the environment to some extent. Economic development in these cities is heavily dependent on carbon-intensive industry. Thus, improving the technical aspects of economic development should be a priority for reducing material use and carbon emissions. However, Qitaihe achieved non-decoupling despite its economic downturn. With the advantages of being close to Harbin, there is an urgent need for this city to promote economic development by expanding the scale of incoming investment to adapt to the existing industrial structure.

3.5. Policy Implications. Northeast China developed into one of the largest industrial centers during the First Five-Year Plan (1953-1957) and made outstanding contributions to the Chinese economy [74]. However, as a consequence of resource depletion, environmental pollution, and commercial reconstruction, the economic development of Northeast China experienced a recession in the 1990s. The implementation of the strategy of "Revitalizing the Old Industrial Base of Northeast China," proposed in 2003, provided a unique opportunity to facilitate the development of the Northeast region [75]. At the same time, economic recovery in the Northeast depended on infrastructure construction and indirectly resulted in the emission of a large amount of $\mathrm{CO}_{2}$. Thus, means by which economic growth could be accelerated while suppressing material consumption and carbon emissions should receive increased attention from policymakers and researchers.

The northeastern region of China has experienced rapid urbanization and industrialization, which has been accompanied by a large amount of material consumption associated with infrastructure construction and carbon emissions. Based on the above research, we provide the following suggestions for promoting the coordinated development of the economy, resources, and the environment in Northeast China.

(1) According to the above results, steel, brick, and cement account for a large proportion of infrastructure materials, which impose a huge load on the environment. Therefore, the local government should increase its direct investment in research on energy-saving and low-emission construction materials in view of future urban infrastructure construction. Innovative energy-efficient construction technologies and material applications will greatly benefit urban ecology. Given that the economic development of the 34 focal cities in Northeast China will still need to rely on infrastructure construction in the coming decades, there is a need to identify infrastructure alternatives, study material flows, and use less energy-intensive construction materials. The increase in prices caused by resource depletion will become an obstacle to promoting economic development, identifying alternative sociotechnical 


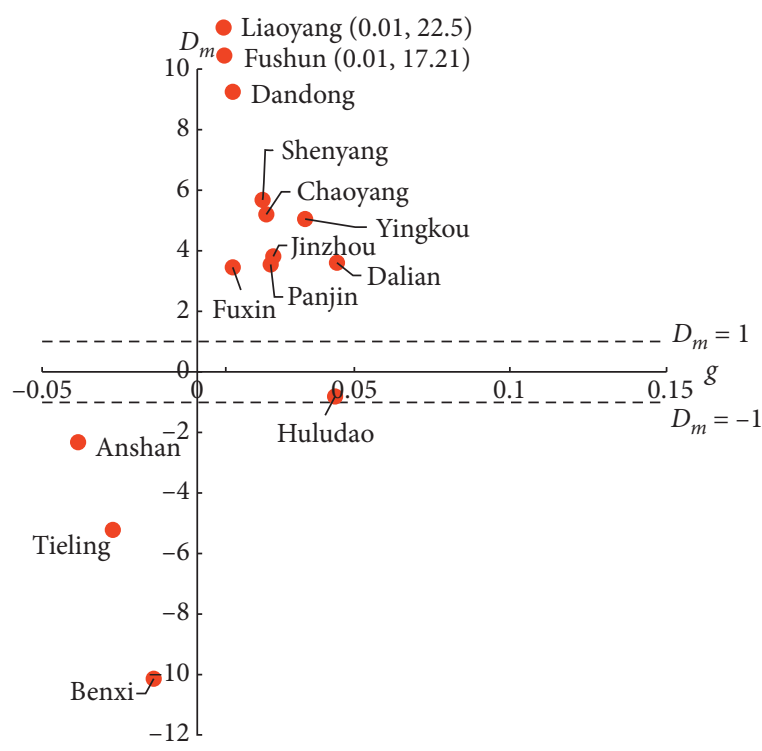

(a)

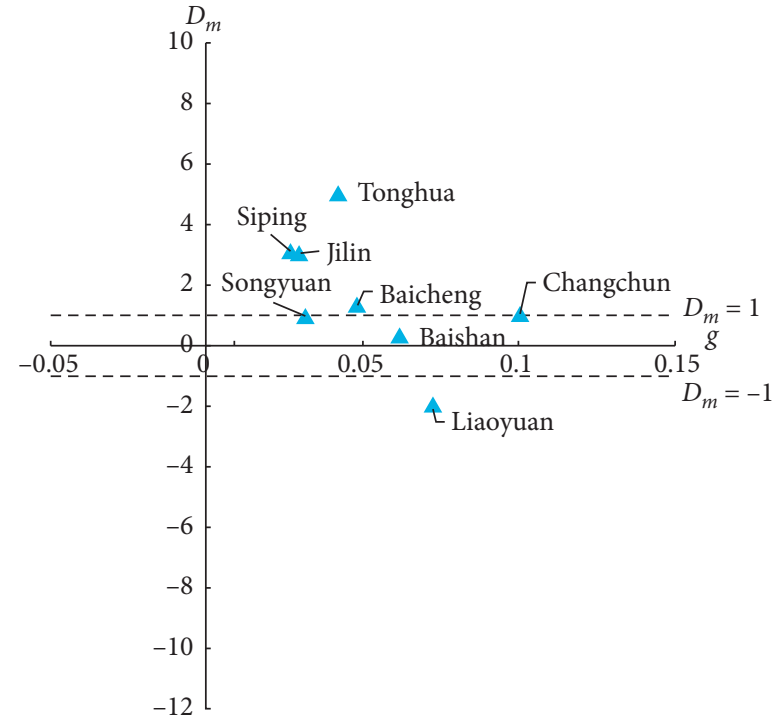

(b)

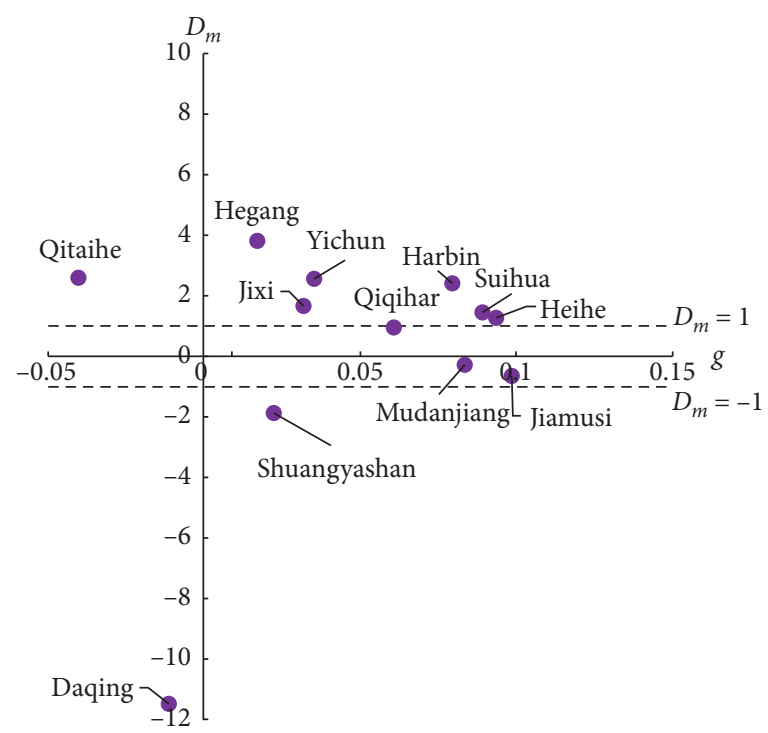

(c)

Figure 11: Decoupling chart of the material consumption of infrastructure construction for 34 cities in Northeast China during 2010-2017 $\left(D_{\mathrm{m}}\right)$. (a) shows the decoupling of the material consumption of infrastructure construction in 14 cities of Liaoning province. (b) shows the decoupling of material consumption of infrastructure construction in eight cities in Jilin province. (c) shows the decoupling of the material consumption of infrastructure construction in 12 cities of Heilongjiang province. $D_{\mathrm{m}}=$ the decoupling indicator for the material consumption of infrastructure; $g=$ geometric average of the growth rate of gross domestic product (GDP) in a certain period.

systems, and reducing GHG emissions. Therefore, the utilization of green modular buildings and lowemission construction materials is of great importance in developing cities. All of these relevant policies need to be developed so that the findings of scientists are bridged with the interests of local officials [76].

(2) From 2010 to 2017, the population size of most cities in Northeast China also decreased (see Tables S4 for population change data). The decline in urban populations is one of the characteristics of urban shrinkage [77-79]. City shrinkage involves the dual loss of population quantity and quality. Additionally, in some shrinking cities, the reduction in demand may be detrimental for the control of the material consumption of infrastructure construction, which slows the decoupling of materials and the environmental impact on GDP. Hence, policymakers and city planners should improve the infrastructure planning system to protect from the risk of overexploitation, thereby increasing the utilization rate of infrastructure in the context of population outflow.

(3) Cities with low per capita carbon emissions that have achieved the absolute decoupling of material 


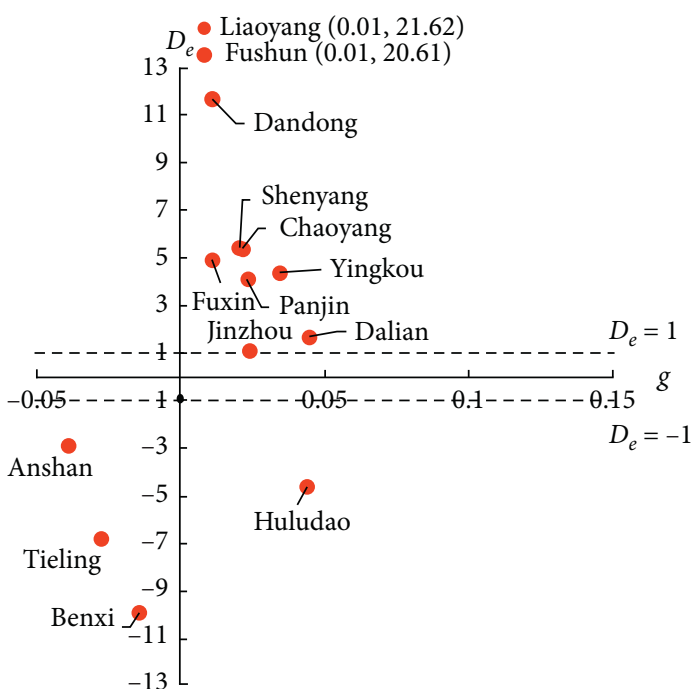

(a)

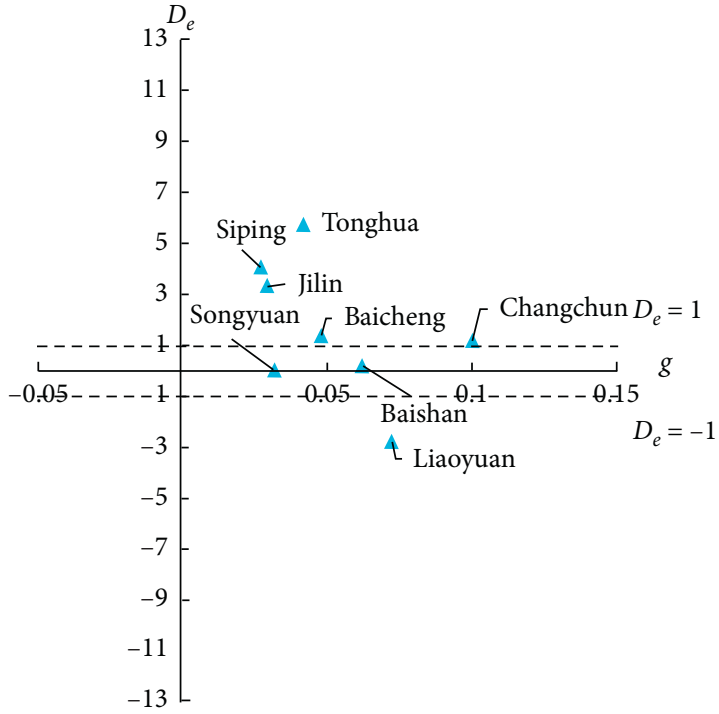

(b)

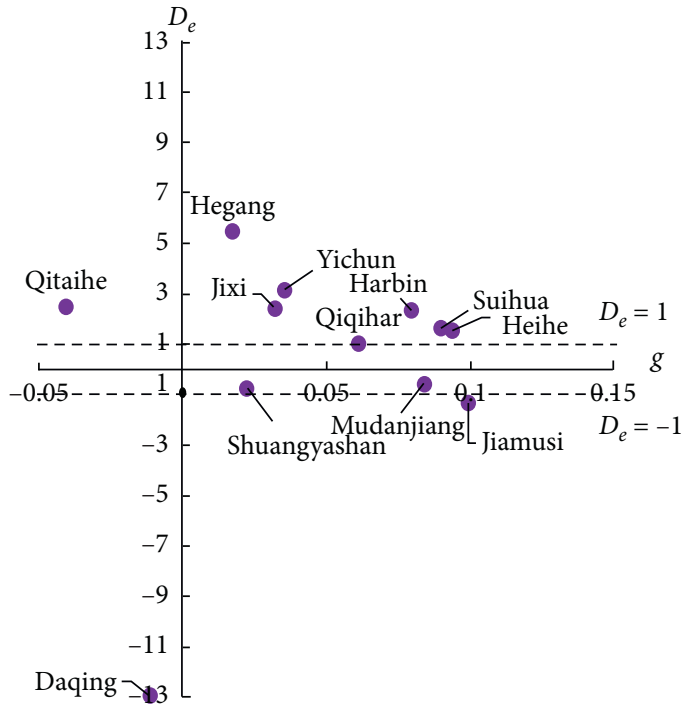

(c)

FIGURE 12: Decoupling chart of the carbon emissions of infrastructure construction for 34 cities in Northeast China from $2010-2017$ ( $\left.D_{\mathrm{e}}\right)$. (a) shows the decoupling of the carbon emissions of infrastructure construction in 14 cities of Liaoning province. (b) shows the decoupling of the carbon emissions of infrastructure construction in eight cities in Jilin province. (c) shows the decoupling of the carbon emissions of infrastructure construction in 12 cities in Heilongjiang province. $D_{\mathrm{e}}=$ decoupling indicator for the material consumption of infrastructure; $g=$ geometric average of gross domestic product (GDP) growth rate in a certain period.

consumption from GDP, such as Suihua, Dandong, and Heihe, which are in less-developed states and losing population, should pay more attention to effectively use the existing infrastructure. This is a vital piece of information for those cities in Northeast China to rationally allocate investment to establish a comprehensive and efficient infrastructure network and enhance management level based on existing infrastructure rather than blindly expanding the scale of construction. Specifically, Huludao, Liaoyuan, Shuangyashan, and Qitaihe have achieved non-decoupling. These types of cities should adjust the structure of their economic development, improve the efficiency of infrastructure construction material use, and change their current excessive dependence on infrastructure for driving the economy. In contrast, Anshan, Benxi, and Daqing are cities well known for the decoupling of their "nonmetal and metal industry" production, material consumption, carbon emissions associated with infrastructure construction, and GDP. These cities have experienced negative economic growth during this period. Through special subsidies and lower taxes, policymakers need to encourage adjusting the industrial structure and establishing a synergistic feedback mechanism between urban 
infrastructure systems and industry with the aim of promoting economic development.

3.6. Limitations. This study aims to analyze temporal-spatial material consumption and carbon emissions in 34 cities and the decoupling conditions of material use and carbon emissions from GDP for infrastructure construction. There are still some limitations in this study. This study ignores the material loss generated by transportation and construction in other stages because of the lack of data. In addition, it is hard to access data to take no account of the disposal of some types of public facilities such as sewer pipes and gas distribution pipes. The lack of data might slightly underestimate the total material consumption and carbon emissions. These factors will be considered in future research to adequately and accurately estimate the material consumption and carbon emissions in infrastructure construction at the city scale.

\section{Conclusions}

In this study, we examined the material consumption and carbon emissions associated with the infrastructure construction of 34 cities in Northeast China.

The material consumption of infrastructure built has increased rapidly from 305.2 million tonnes to 339.9 million tonnes from 2010-2012 and then slightly decreased to 304.9 million tonnes from 2012-2015, followed by a significant decline to 199.6 million tonnes by 2017. The total carbon emissions of infrastructure construction reached 77.7 million tonnes, 87.0 million tonnes, 81.3 million tonnes, and 54.3 million tonnes, across several sample years, respectively. Material consumption and carbon emissions varied among cities, and most carbon emissions were concentrated in Shenyang, Dalian, Changchun, and Harbin. Additionally, the material consumption intensity and carbon emission intensity of infrastructure construction in most cities decreased, indicating that the efficiency of material use and emission efficiency had increased. The proportion of energy-intensive materials, such as cement, brick, and steel continued to increase, which may thus have comparatively higher environmental impacts.

We also found that the overall distribution of infrastructure construction was uneven. The distribution of infrastructure construction was consistent with the disparity in economic development across cities. Based on the overall trend in development from 2010-2017 across the 34 cities, there is still a long way to go before the complete decoupling of material consumption or carbon emissions with GDP can be achieved. Over the next few decades, there is an urgent need to increase the application of green modular buildings and improve the infrastructure planning system given that an increased amount of infrastructure is being built to support the development of the urban economy. This study provides comparable spatial-temporal city-level material consumption and carbon emissions data for future research on the relationships between economic development and infrastructure construction in Northeast China. Moreover, this paper also aimed to provide practical values that could serve as references for other cities to achieve sustainable development.

\section{Data Availability}

The data used to support the findings of this study are available from the corresponding author and government statistical yearbook upon request.

\section{Conflicts of Interest}

The authors declare that they have no conflicts of interest.

\section{Acknowledgments}

This research was supported by the National Natural Science Foundation of China (52070034, 41871204, and 71403175) and Fundamental Research Funds for the Central Universities (N182502045). The authors appreciate the helpful feedback from the editor and anonymous reviewers.

\section{Supplementary Materials}

Table S1: material intensity in different infrastructures in China. Table S2: embodied carbon emission intensity of construction materials in China $\left(t \mathrm{CO}_{2} / t\right)$. Table S3: values of GDP in 34 cities at four points during the study period (2010, 2012, 2015, and 2017) (unit: $1 \times 10^{4}$ yuan). Table S4: values of population in 34 cities at four points during the study period (2010, 2012, 2015, and 2017) (unit: $1 \times 10^{4}$ person). Figure S1: in three time periods, GDP and population growth rate of 34 cities in Northeast China. (Supplementary Materials)

\section{References}

[1] S. Thacker, D. Adshead, M. Fay et al., "Infrastructure for sustainable development," Nature Sustainability, vol. 2, no. 4, pp. 324-331, 2019.

[2] H. Wang, H. Schandl, X. Wang et al., "Measuring progress of China's circular economy," Resources, Conservation and Recycling, vol. 163, 2020.

[3] M. Porhincak and A. Estokova, "Comparative analysis of environmental performance of building materials towards sustainable construction" in Proceedings of the 16th International Conference on Process Integration, Modelling and Optimisation for Energy Saving and Pollution Reduction, Modelling and Optimisation for Energy Saving and Pollution Reduction, P. Varbanov, J. J. Klemes, P. Seferlis, A. I. Papadopoulos, S. Voutetakis, and S. Pierucci, Eds., Aidic Servizi Srl, Milano, Italy, pp. 1291-1296, October 2013.

[4] H. Schandl, Y. Lu, N. Che et al., "Shared socio-economic pathways and their implications for global materials use," Resources, Conservation and Recycling, vol. 160, Article ID 104866, 2020.

[5] W. Zhao, H. Yu, S. Liang, W. Zhang, and Z. Yang, "Resource impacts of municipal solid waste treatment systems in Chinese cities based on hybrid life cycle assessment," Resources, Conservation and Recycling, vol. 130, pp. 215-225, 2018.

[6] J. Yang, W. L. Liu, Y. H. Li, X. M. Li, and Q. S. Ge, "Simulating intraurban land use dynamics under multiple scenarios based 
on fuzzy cellular automata: a case study of Jinzhou District, Dalian," Complexity, vol. 2018, Article ID 7202985, 2018.

[7] J. Yang, S. H. Jin, X. M. Xiao et al., "Local climate zone ventilation and urban land surface temperatures: towards a performance-based and wind-sensitive planning proposal in megacities," Sustainable Cities and Society, vol. 47, 2019.

[8] L. Chen, S. Liang, M. Liu et al., "Trans-provincial health impacts of atmospheric mercury emissions in China," Nature Communications, vol. 10, p. 1484, 2019.

[9] J. Qi, Y. Wang, S. Liang et al., "Primary suppliers driving atmospheric mercury emissions through global supply chains," One Earth, vol. 1, no. 2, pp. 254-266, 2019.

[10] Y. Yu, L. Zhou, W. Zhou et al., "Decoupling environmental pressure from economic growth on city level: the case study of Chongqing in China," Ecological Indicators, vol. 75, pp. 27-35, 2017.

[11] S. Chen, B. Chen, K. Feng et al., "Physical and virtual carbon metabolism of global cities," Nature Communications, vol. 11, p. 182, 2020.

[12] C. Lin, J. Qi, S. Liang et al., "Saving less in China facilitates global $\mathrm{CO}_{2}$ mitigation," Nature Communications, vol. 11, p. 1358, 2020.

[13] H. Wang, H. Dai, L. Dong et al., "Co-benefit of carbon mitigation on resource use in China," Journal of Cleaner Production, vol. 174, pp. 1096-1113, 2018.

[14] Y. Yu, D. Chen, B. Zhu, and S. Hu, "Eco-efficiency trends in China, 1978-2010: decoupling environmental pressure from economic growth," Ecological Indicators, vol. 24, pp. 177-184, 2013.

[15] D. B. Müller, G. Liu, A. N. Løvik et al., "Carbon emissions of infrastructure development," Environmental Science \& Technology, vol. 47, no. 20, pp. 11739-11746, 2013.

[16] L. Jiang, B. Xue, Z. Ma, L. Yu, B. Huang, and X. Chen, "A lifecycle based co-benefits analysis of biomass pellet production in China," Renewable Energy, vol. 154, pp. 445-452, 2020.

[17] A. Ansar, B. Flyvbjerg, A. Budzier, and D. Lunn, "Does infrastructure investment lead to economic growth or economic fragility? evidence from China," Oxford Review of Economic Policy, vol. 32, no. 3, pp. 360-390, 2016.

[18] H. Zhang, L. Li, T. Chen, and V. Li, "Where will China's real estate market go under the economy's new normal?" Cities, vol. 55, pp. 42-48, 2016.

[19] J. E. Fernández, "Resource consumption of new urban construction in China," Journal of Industrial Ecology, vol. 11, no. 2, pp. 99-115, 2007.

[20] J. P. Xi, "Work together to build a win-win, equitable and balanced governance mechanism on climate change," in Proceedings of the United Nations Climate Change Conference, Paris, France, November 2015.

[21] Z. Han, Y. Long, X. Wang, and J. Hou, "Urban redevelopment at the block level: methodology and its application to all Chinese cities," Environment \& Planning B Urban Analytics \& City Science, 2019.

[22] J. Han, W.-Q. Chen, L. Zhang, and G. Liu, "Uncovering the spatiotemporal dynamics of urban infrastructure development: a high spatial resolution material stock and flow analysis," Environmental Science \& Technology, vol. 52, no. 21, pp. 12122-12132, 2018.

[23] H. Schandl, M. Fischer-Kowalski, J. West et al., "Global material flows and resource productivity: forty years of evidence," Journal of Industrial Ecology, vol. 22, no. 4, pp. 827-838, 2018.

[24] F. Krausmann, D. Wiedenhofer, C. Lauk et al., "Global socioeconomic material stocks rise 23 -fold over the 20 th century and require half of annual resource use," Proceedings of the National Academy of Sciences, vol. 114, no. 8, pp. 1880-1885, 2017.

[25] H. Schandl, S. Hatfield-Dodds, T. Wiedmann et al., "Decoupling global environmental pressure and economic growth: scenarios for energy use, materials use and carbon emissions," Journal of Cleaner Production, vol. 132, pp. 45-56, 2016.

[26] A. Miatto, H. Schandl, T. Fishman, and H. Tanikawa, "Global patterns and trends for non-metallic minerals used for construction," Journal of Industrial Ecology, vol. 21, no. 4, pp. 924-937, 2017.

[27] T. Dai and W. Wang, "The characteristics and trends of socioeconomic metabolism in China," Journal of Industrial Ecology, vol. 22, no. 5, pp. 1228-1240, 2017.

[28] H. Wang, S. Hashimoto, Y. Moriguchi, Q. Yue, and Z. Lu, "Resource use in growing China," Journal of Industrial Ecology, vol. 16, no. 4, pp. 481-492, 2012.

[29] F. Ma, H. Wang, B. Zhu et al., "Material footprint of a fastindustrializing region in China, Part 1: exploring the materialization process of Liaoning Province," Resources, Conservation and Recycling, vol. 134, pp. 228-238, 2018.

[30] T. M. Baynes and J. K. Musango, "Estimating current and future global urban domestic material consumption," Environmental Research Letters, vol. 13, 2018.

[31] Q. Liu, Z. Cao, X. Liu et al., "Product and metal stocks accumulation of China's megacities: patterns, drivers, and implications," Environmental Science \& Technology, vol. 53, no. 8, pp. 4128-4139, 2019.

[32] J. Guo, T. Fishman, Y. Wang et al., "Urban development and sustainability challenges chronicled by a century of construction material flows and stocks in Tiexi, China," Journal of Industrial Ecology, vol. 351, 2020.

[33] E. Müller, L. M. Hilty, R. Widmer, M. Schluep, and M. Faulstich, "Modeling metal stocks and flows: a review of dynamic material flow analysis methods," Environmental Science \& Technology, vol. 48, no. 4, pp. 2102-2113, 2014.

[34] M. Fischer-Kowalski, F. Krausmann, S. Giljum et al., "Methodology and indicators of economy-wide material flow accounting," Journal of Industrial Ecology, vol. 15, no. 6, pp. 855-876, 2011.

[35] H. Liang, L. Dong, H. Tanikawa, N. Zhang, Z. Gao, and X. Luo, "Feasibility of a new-generation nighttime light data for estimating in-use steel stock of buildings and civil engineering infrastructures," Resources, Conservation and Recycling, vol. 123, pp. 11-23, 2017.

[36] H. Tanikawa, T. Fishman, K. Okuoka, and K. Sugimoto, "The weight of society over time and space: a comprehensive account of the construction material stock of Japan," Journal of Industrial Ecology, vol. 19, pp. 778-791, 2015.

[37] T. Fishman, H. Schandl, H. Tanikawa, P. Walker, and F. Krausmann, "Accounting for the material stock of nations," Journal of Industrial Ecology, vol. 18, no. 3, pp. 407-420, 2014.

[38] F. Shi, T. Huang, H. Tanikawa, J. Han, S. Hashimoto, and Y. Moriguchi, "Toward a low carbon-dematerialization society," Journal of Industrial Ecology, vol. 16, no. 4, pp. 493-505, 2012.

[39] T. Fishman, H. Schandl, and H. Tanikawa, "The socio-economic drivers of material stock accumulation in Japan's prefectures," Ecological Economics, vol. 113, pp. 76-84, 2015.

[40] J. He, Q. Yue, Y. Li, F. Zhao, and H. Wang, "Driving force analysis of carbon emissions in China's building industry: 2000-2015," Sustainable Cities and Society, vol. 60, Article ID 102268, 2020. 
[41] D. Wiedenhofer, J. K. Steinberger, N. Eisenmenger, and W. Haas, "Maintenance and expansion: modeling material stocks and flows for residential buildings and transportation networks in the EU25," Journal of Industrial Ecology, vol. 19, no. 4 , pp. 538-551, 2015.

[42] M. Hu, S. Pauliuk, T. Wang, G. Huppes, E. van der Voet, and D. B. Müller, "Iron and steel in Chinese residential buildings: a dynamic analysis," Resources, Conservation and Recycling, vol. 54, no. 9, pp. 591-600, 2010.

[43] S. Hashimoto, H. Tanikawa, and Y. Moriguchi, "Framework for estimating potential wastes and secondary resources accumulated within an economy-a case study of construction minerals in Japan," Waste Management, vol. 29, no. 11, pp. 2859-2866, 2009.

[44] J. Han and W.-N. Xiang, "Analysis of material stock accumulation in China's infrastructure and its regional disparity," Sustainability Science, vol. 8, no. 4, pp. 553-564, 2013.

[45] H. Liang, H. Tanikawa, Y. Matsuno, and L. Dong, "Modeling in-use steel stock in China's buildings and civil engineering infrastructure using time-series of DMSP/OLS nighttime lights," Remote Sensing, vol. 6, no. 6, pp. 4780-4800, 2014.

[46] F. Kleemann, J. Lederer, H. Rechberger, and J. Fellner, "GISbased analysis of Vienna's material stock in buildings," Journal of Industrial Ecology, vol. 21, no. 2, pp. 368-380, 2017.

[47] K. Condeixa, A. Haddad, and D. Boer, "Material flow analysis of the residential building stock at the city of Rio de Janeiro," Journal of Cleaner Production, vol. 149, pp. 1249-1267, 2017.

[48] C. Mesta, R. Kahhat, and S. Santa-Cruz, "Geospatial characterization of material stock in the residential sector of a Latin-American city," Journal of Industrial Ecology, vol. 23, no. 1, pp. 280-291, 2019.

[49] H. Tanikawa and S. Hashimoto, "Urban stock over time: spatial material stock analysis using 4d-GIS," Building Research \& Information, vol. 37, no. 5-6, pp. 483-502, 2009.

[50] H. Dan, Y. Fang, Y. Zhao et al., "Input, stocks and output flows of urban residential building system in Beijing city, China from 1949 to 2008," Resources Conservation \& Recycling, vol. 54, pp. 1177-1188, 2010.

[51] C. Huang, J. Han, and W.-Q. Chen, "Changing patterns and determinants of infrastructures' material stocks in Chinese cities," Resources, Conservation and Recycling, vol. 123, pp. 47-53, 2017.

[52] K. A. Marcellus-Zamora, P. M. Gallagher, S. Spatari, and H. Tanikawa, "Estimating materials stocked by land-use type in historic urban buildings using spatio-temporal analytical tools," Journal of Industrial Ecology, vol. 20, no. 5, pp. 1025-1037, 2016.

[53] H. Schandl, R. Marcos-Martinez, T. Baynes, Z. Yu, A. Miatto, and H. Tanikawa, "A spatiotemporal urban metabolism model for the Canberra suburb of Braddon in Australia," Journal of Cleaner Production, vol. 265, p. 121770, 2020.

[54] T. Huang, F. Shi, H. Tanikawa, J. Fei, and J. Han, "Materials demand and environmental impact of buildings construction and demolition in China based on dynamic material flow analysis," Resources, Conservation and Recycling, vol. 72, pp. 91-101, 2013.

[55] Z. Guo, D. Hu, Z. Zhang, P. Zhang, and X. Zhang, "Material metabolism and lifecycle GHG emissions of urban road system (URS)," Journal of Cleaner Production, vol. 165, pp. 243-253, 2017.

[56] NBS, Statistical Yearbook-2010 (Each City of 34 PrefectureLevel Cities in Northeast China), China Statistics Press, Beijing, China, 2011.
[57] NBS, Statistical Yearbook-2012 (Each City of 34 PrefectureLevel Cities in Northeast China), China Statistics Press, Beijing, China, 2013.

[58] NBS, Statistical Yearbook-2015 (Each City of 34 PrefectureLevel Cities in Northeast China), China Statistics Press, Beijing, China, 2016.

[59] NBS, Statistical Yearbook-2017 (Each City of 34 PrefectureLevel Cities in Northeast China), China Statistics Press, Beijing, China, 2018.

[60] OECD, Indicators to Measure Decoupling of Environmental Pressure from Economic Growth, OECD, Paris, France, 2002.

[61] Z. Lu, H. Wang, and Q. Yue, "Decoupling indicators: quantitative relationships between resource use, waste emission and economic growth," Resources Science, vol. 33, pp. 2-9, 2011.

[62] B. Commoner, "The environmental cost of economic growth," Chemistry in Britain, vol. 8, no. 2, p. 52, 1972.

[63] P. Ehrlich and J. Holdren, A Bulletin Dialogue on the "Closing Circle". Critique: One Dimensional Ecology, Bulletin of the Atomic Scientists, Chicago, IL, USA, 1972.

[64] H. Wang, S. Hashimoto, Q. Yue, Y. Moriguchi, and Z. Lu, "Decoupling analysis of four selected countries," Journal of Industrial Ecology, vol. 17, no. 4, pp. 618-629, 2013.

[65] K. Shan, Q. Wu, P. Cao, and Q. Guo, "Empirical analysis of regional economic competitiveness at the northeastern China and inner Mongolia", in Electronic Information and Electrical Engineering, B. J. Chen, V. Hu, and D. Kong, Eds., pp. 769-773, Atlantis Press, Paris, France, 2012.

[66] C. Council, "National action plan for energy development strategy," 2014.

[67] Q. Zhang, Z. Li, G. Wang, and H. Li, "Study on the impacts of natural gas supply cost on gas flow and infrastructure deployment in China," Applied Energy, vol. 162, pp. 1385-1398, 2016.

[68] C. Zhang, W.-Q. Chen, and M. Ruth, "Measuring material efficiency: a review of the historical evolution of indicators, methodologies and findings," Resources, Conservation and Recycling, vol. 132, pp. 79-92, 2018.

[69] R. Gudipudi, T. Fluschnik, A. G. C. Ros, C. Walther, and J. P. Kropp, "City density and $\mathrm{CO}_{2}$ efficiency," Energy Policy, vol. 91, pp. 352-361, 2016.

[70] Q. Tang, P. Shi, Z. Yuan, S. Shi, X. Xu, and T. Katsumi, "Potential of zero-valent iron in remediation of Cd(II) contaminated soil: from laboratory experiment, mechanism study to field application," Soils and Foundations, vol. 59, no. 6, pp. 2099-2109, 2019.

[71] W. Sun, Y. Zhou, J. Lv, and J. Wu, "Assessment of multi-air emissions: case of particulate matter (dust), $\mathrm{SO}_{2}, \mathrm{NO}$ and $\mathrm{CO}_{2}$ from iron and steel industry of China," Journal of Cleaner Production, vol. 232, pp. 350-358, 2019.

[72] W. Sun, Q. Wang, Z. Zheng, and J. Cai, "Material-energyemission nexus in the integrated iron and steel industry," Energy Conversion and Management, vol. 213, Article ID 112828, 2020.

[73] F. Dong, B. Yu, T. Hadachin et al., "Drivers of carbon emission intensity change in China," Resources, Conservation and Recycling, vol. 129, pp. 187-201, 2018.

[74] P. Zhang, "Revitalizing old industrial base of Northeast China: process, policy and challenge," Chinese Geographical Science, vol. 18, no. 2, pp. 109-118, 2008.

[75] B. Xue, X. Xiao, and J. Li, "Identification method and empirical study of urban industrial spatial relationship based on POI big data: a case of Shenyang City, China," Geography and Sustainability, 2020. 
[76] B. Xue, "Honing the climate change message," Science, vol. 348 , no. 6237 , p. 872, 2015.

[77] Y.-M. Joo and B. Seo, "Dual policy to fight urban shrinkage: Daegu, South Korea," Cities, vol. 73, pp. 128-137, 2018.

[78] Y. Long, W. Zhai, Y. Shen, and X. Ye, "Understanding uneven urban expansion with natural cities using open data," Landscape and Urban Planning, vol. 177, pp. 281-293, 2018.

[79] Y. Long and Y. Ye, "Measuring human-scale urban form and its performance," Landscape and Urban Planning, vol. 191, no. 3, 2019. 